\title{
UNIVERSIDADE DE SÃO PAULO ESCOLA DE ENFERMAGEM DE RIBEIRÃO PRETO
}

ANGELINA MODA MACHADO

Atitudes de familiares de portadores de transtornos mentais frente aos transtornos mentais: a influência do grupo de autoajuda 


\section{ANGELINA MODA MACHADO}

\section{Atitudes de familiares de portadores de transtornos mentais frente aos transtornos mentais: a influência do grupo de autoajuda}
Dissertação apresentada à Escola de Enfermagem de Ribeirão Preto da Universidade de São Paulo, para a obtenção do título de Mestre em Ciências, Programa Enfermagem Psiquiátrica.

Área de Concentração: Enfermagem Psiquiátrica.

Linha de pesquisa: Enfermagem Psiquiátrica: o doente, a doença e as práticas terapêuticas.

Orientador: Prof. Dr. Luiz Jorge Pedrão 
Autorizo a reprodução e divulgação total ou parcial deste trabalho, por qualquer meio convencional ou eletrônico, para fins de estudo e pesquisa, desde que citada à fonte.

FICHA CATALOGRÁFICA

Machado, Angelina Moda

Atitudes de familiares de portadores de transtornos mentais frente aos transtornos mentais: a influência do grupo de autoajuda. Ribeirão Preto, 2011.

68 p. : il. ; $30 \mathrm{~cm}$

Dissertação de Mestrado, apresentada à Escola de Enfermagem de Ribeirão Preto/USP. Área de concentração: Enfermagem Psiquiátrica.

Orientador: Pedrão, Luiz Jorge.

1. Atitudes. 2. Transtorno Mental. 3. Família. 4.. Grupo de autoajuda. 


\section{FOLHA DE APROVAÇÃO}

Angelina Moda Machado

Atitudes de familiares de portadores de transtornos mentais frente aos transtornos mentais: a influência do grupo de autoajuda.

Dissertação apresentada à Escola de Enfermagem de Ribeirão Preto da Universidade de São Paulo, para a obtenção do título de Mestre em Ciências Programa Enfermagem Psiquiátrica.

Aprovado em:

Banca Examinadora

Prof(a). Dr(a). Instituição

Julgamento Assinatura

$\operatorname{Prof}(\mathrm{a}) . \operatorname{Dr}(\mathrm{a})$. Instituição

Julgamento Assinatura

Prof(a). Dr(a). Instituição

Julgamento Assinatura 


\section{AGRADECIMENTOS}

Ao Prof. Dr. Luiz Jorge Pedrão, que desde o início de minha formação me orienta com muita dedicação, sempre confiando no meu trabalho, transmitindo muita sabedoria e inspiração no amadurecimento dos meus conhecimentos, pela compreensão e pela amizade.

Ao Prof. Dr. Moacyr, pelo apoio estatístico desde o inicio do estudo.

As Meus Pais Dirceu e Luiza, sempre me incentivando, encorajando e orientando sobre os caminhos corretos a seguir, e, com muito carinho e apoio, não mediram esforços para que eu chegasse até esta etapa de minha vida.

Ao Meu Noivo Lucas, pelo apoio nos momentos difíceis, pela paciência quase perdida em alguns momentos e por estar ao meu lado oferecendo apoio necessário desde o inicio desde trabalho.
À Fundação de Amparo à Pesquisa do Estado de São Paulo, pela concessão de bolsa de mestrado e pelo apoio para realização desta pesquisa. 


\section{RESUMO}

MACHADO, A. M. Atitudes de familiares de portadores de transtornos mentais frente aos transtornos mentais: a influência do grupo de autoajuda. 2011. $68 \mathrm{f}$. Dissertação (Mestrado) - Escola de Enfermagem de Ribeirão Preto, Universidade de São Paulo, Ribeirão Preto, 2011.

Diferentes pessoas podem ter atitudes diferentes frente a um mesmo objeto, mas esta diversidade de posicionamento não deve ser encarada como características idiossincráticas ou estáveis, não nascem num vazio social, são fruto de interação social, de processo de comparação, identificação e diferenciação social que permite situar uma posição frente a outras em um determinado momento. A família, enquanto grupo, atravessa os tempos passando por inúmeras transformações e críticas, sem se afastar da responsabilidade e das exigências dos papéis socialmente atribuídos a ela. $\mathrm{O}$ transtorno mental permanece ainda obscuro, não existindo uma causa que o explique como tão estigmatizante, mas, o adoecer psíquico, é facilmente percebido, pois, os indivíduos que adoecem, apresentam comportamentos diferentes daqueles normalmente aceitos pela sociedade. Os grupos de autoajuda são homogêneos, seus participantes passam pelo mesmo sofrimento, são de apoio mútuo e educacional, a liderança vem do interior do grupo, reporta-se somente a um único evento desestruturador de vida, os membros participam voluntariamente, sem fins lucrativos, objetivam o crescimento pessoal dos integrantes e tem caráter anônimo e confidencial. Partindo-se do princípio de que as atitudes frente aos transtornos mentais e seus portadores são passíveis de serem trabalhadas e modificadas, mesmo sendo necessário um trabalho ao longo de um grande período de tempo, pois envolve aspectos formadores da personalidade, este estudo teve como objetivo mostrar as atitudes frente aos transtornos mentais de familiares de portadores de transtornos mentais que participam de grupo de autoajuda, de familiares que não participam de grupos desta natureza e estudar comparativamente as atitudes destes dois grupos. Para isso, 20 familiares de portadores de transtornos mentais, sendo 10 familiares que participam de um grupo de autoajuda e 10 familiares que nunca participaram de grupo de autoajuda, responderam a um questionário com uma parte sobre os seus dados pessoais e a outra parte com perguntas abertas sobre sua proximidade com o seu parente portador de transtorno mental e a escala de atitudes "Opiniões Sobre os Transtornos Mentais" (OTM). Os resultados mostraram que em ambos os grupos a faixa etária dos familiares está acima dos 50 anos, a maioria são mães, casadas, católicas, com tempo de convívio com o parente portador de transtorno mental acima de 5 anos, a esquizofrenia é o transtorno mais frequente, sendo melhor a situação econômica dos familiares participantes do grupo de autoajuda. Os resultados da OTM, analisados de forma estatística utilizando-se o teste de Mann-Whitney $U$ mostraram uma influência positiva do grupo de autoajuda nas atitudes de familiares de portadores de transtornos mentais frente aos transtornos mentais e seus parentes portadores desses transtornos, mas essa influência mostrou-se relativa, pois, os dois grupos, revelaram ainda atitudes autoritárias, restritivas e discriminadoras, levando à conclusão de que o grupo de autoajuda é extremamente importante e uma expressiva ferramenta de apoio, mas para uma real mudança de atitudes nos aspectos considerados, são necessárias modalidades terapêuticas mais específicas e que utilizam intervenções mais focadas.

Palavras-chave: Atitudes. Transtorno mental. Família. Grupos de autoajuda. 


\begin{abstract}
MACHADO, A. M. Attitudes of mental disorder patients' relatives towards the mental disorders: the influence of a self-help group. 2011.68 p. Master's Thesis - University of São Paulo at Ribeirão Preto College of Nursing. 2011.
\end{abstract}

Different people may have different attitudes towards a same object, but this range of positions should not be seen as idiosyncratic or stable characteristics. They are not born in a social void, but are the fruit of social interaction, of a comparison, identification and social distinction process that permits situating one position towards others at a given time. As a group, the family evolves going through countless transformations and criticism, without distancing itself from the responsibility and requirements of the roles it is socially attributed. Mental disorder is still obscure, without a cause to explain the extent of its stigma, but psychic illness is easily perceived, as the people who get ill display behaviors different from what society normally accepts. Self-help groups are homogeneous. Their participants go through the same suffering. The groups provide mutual support and are educational. Leadership comes from within the group, which only refers to a single deconstructive event in life. Members participate voluntarily, without aiming for profit. The groups aim for their members' personal growth and are anonymous and confidential. Departing from the principle that attitudes towards mental disorders and their patients can be addressed and modified, although demanding long-term work, as it involves personality-building aspects, this study aimed to show the attitudes towards mental disorders of family members of mental disorder patients who participate in a self-help group, of family members who do not participate in this kind of groups, and to comparatively study these two groups' attitudes. Thus, 20 relatives of mental disorder patients, ten of whom participate in a self-help group and ten who had never participated in a self-help group, answered a questionnaire. One part referred to their personal data, while the other part contained open questions on their proximity with their relative suffering from a mental disorder, as well as the attitude scale "Opinions on Mental Disorders" (OMD). The results showed that, in both groups, the relatives' age range is over 50 years, most are mothers, married, Catholic, have lived with the relative suffering from the mental disorder for more than five years, schizophrenia is the most frequent disorder and the relatives who participate in the self-help group display a better socio-economic situation. Statistical analysis of the OMD results, using Mann-Whitney's U-test, showed a positive influence of the self-help group on the attitudes of mental disorder patients' relatives towards the mental disorders and their relatives suffering from these disorders. This influence revealed to be relative though, as the two groups also revealed authoritarian, restrictive and discriminatory attitudes, leading to the conclusion that the self-help group is extremely important and a meaningful support tool. To achieve an actual change in attitudes towards the aspects under analysis though, more specific therapeutic modes are needed, which use more focused interventions.

Key words: Attitudes, Mental Disorder, Family, Self-help Groups. 


\section{RESUMEN}

MACHADO, A. M. Actitudes de familiares de portadores de trastornos mentales ante los trastornos mentales: la influencia del grupo de autoayuda. $2011.68 \mathrm{~h}$. Disertación (Maestría) - Escuela de Enfermería de Ribeirão Preto. Universidad de São Paulo. 2011.

Diferentes individuos pueden adoptar actitudes diferentes ante un mismo objeto, pero esta diversidad de posicionamiento no debe ser encarada como características idiosincráticas o estables, no nacen en un vacío social, resultan de interacción social, de un proceso de comparación, identificación y diferenciación social que permite situar una posición ante otras en un determinado momento. La familia, como grupo, atraviesa los tiempos pasando por innúmeras transformaciones y críticas, sin alejarse de la responsabilidad y de las exigencias de los papeles socialmente atribuidos a ella. El trastorno mental todavía sigue obscuro. No existe una causa que lo explique como tan estigmatizante, pero el adolecer psíquico se percibe fácilmente, ya que los individuos que adolecen presentan comportamientos diferentes de aquellos normalmente aceptados por la sociedad. Los grupos de auto-ayuda son homogéneos. Sus participantes pasan por el mismo sufrimiento. Son de apoyo mutuo y educacional. El liderazgo viene del interior del grupo. Se reporta solamente a un único evento desarticulador de la vida. Los miembros participan voluntariamente, sin fines lucrativos. Visan al crecimiento personal de los integrantes y tienen carácter anónimo y confidencial. Partiéndose del principio que las actitudes ante los trastornos mentales y sus portadores pueden ser trabajadas y modificadas, aunque siendo necesario un trabajo a lo largo de un largo período de tiempo, ya que abarca aspectos formadores de la personalidad, la finalidad de este estudio fue mostrar las actitudes ante los trastornos mentales de familiares de portadores de trastornos mentales que participan de grupo de autoayuda, de familiares que no participan de grupos de este tipo y estudiar comparativamente las actitudes de estos dos grupos. Para eso, 20 familiares de portadores de trastornos mentales, siendo 10 familiares que participan de un grupo de autoayuda y 10 familiares que jamás participaron de grupo de autoayuda, respondieron a un cuestionario con una parte sobre sus datos personales y otra parte con preguntas abiertas sobre su proximidad con su familiar portador de trastorno mental y la escala de actitudes "Opiniones Sobre los Trastornos Mentales" (OTM). Los resultados mostraron que, en ambos grupos, el rango de edad de los familiares es superior a 50 años, la mayoría son madres, casadas, católicas, con tiempo de convivio con el familiar portador de trastorno mental superior a 5 años, la esquizofrenia es el trastorno más frecuente, siendo mejor la situación económica de los familiares participantes del grupo de autoayuda. Los resultados de la OTM, analizados de forma estadística, mediante el test de Mann-Whitney $U$, mostraron una influencia positiva del grupo de autoayuda en las actitudes de familiares de portadores de trastornos mentales ante los trastornos mentales y sus familiares portadores de esos trastornos, pero esa influencia se mostró relativa, pues los dos grupos también revelaron actitudes autoritarias, restrictivas y discriminadoras, llevando a la conclusión de que el grupo de autoayuda es extremamente importante y una expresiva herramienta de apoyo. Sin embargo, para un real cambio de actitudes en los aspectos considerados, son necesarias modalidades terapéuticas más específicas y que utilizan intervenciones más enfocadas.

Palabras clave: Actitudes, Trastorno Mental, Familia, Grupos de Autoayuda. 


\section{SUMÁRIO}

1. INTRODUÇÃO

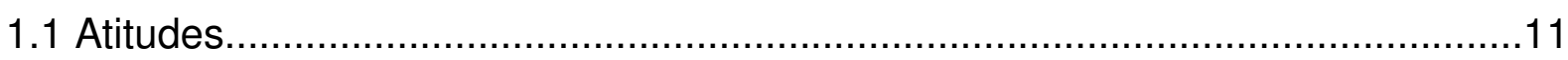

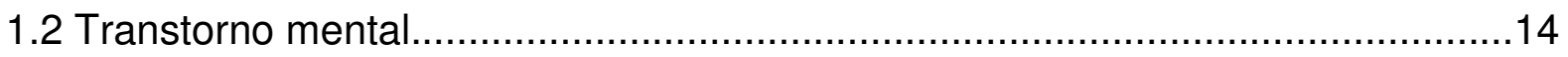

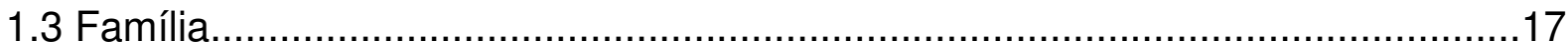

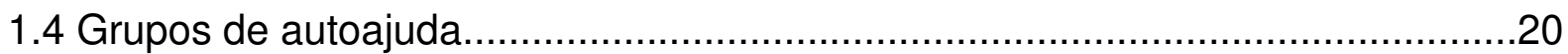

2. OBJETIVOS

3. METODOLOGIA

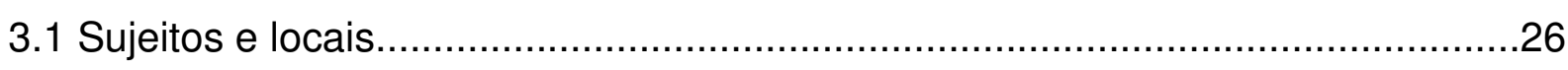

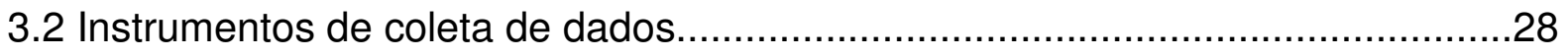

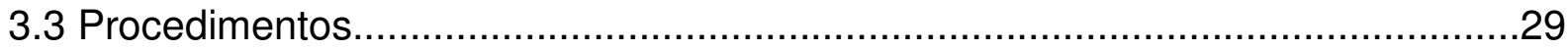

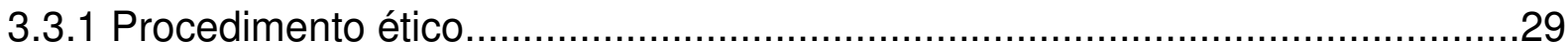

3.3.2 Aplicação dos instrumentos - Questionário e OTM.......................................30

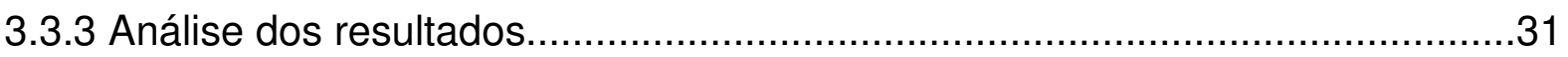

4. RESULTADOS

4.1 Dados obtidos através do questionário e classificação

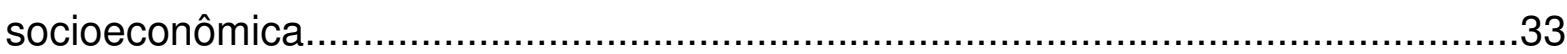

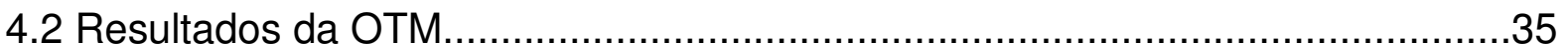

5. DISCUSSÃO

6. CONCLUSÃO

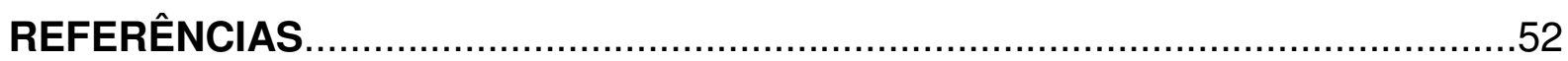

APÊNDICES

ANEXOS 
Quando pequenos, aprende-se a ter medo das pessoas loucas, ou a rir da forma diferente como essas se apresentam ou se comportam. O Movimento Antimanicomial, que engendrou a Lei 10216/2001, da Reforma Psiquiátrica e instituiu o dia 18 de maio como data de luta por novas formas de tratamento dos transtornos mentais, começa a modificar esses comportamentos. Porém, o fundamental a ser destacado é a nova atitude que se deve ter frente aos transtornos mentais. Em vez de excluir, jogar pedra, ou ridicularizar, deve-se enxergar essas pessoas com os olhos da compreensão, tolerância, solidariedade e fraternidade. Para isso, não é necessário o manicômio, e, sim, apenas que a sociedade as aceite do jeito que elas são.

Com o Movimento da Reforma Psiquiátrica, houve transformação de vários hospitais psiquiátricos tradicionais e o surgimento de Centros de Atenção Psicossocial (CAPS) e ambulatórios de saúde mental, voltados para a reabilitação psicossocial (AMARANTE, 2001), mas, de certa forma, a assistência psiquiátrica não apresentou, ainda, transformação satisfatória, levando ao entendimento de que a mudança no modo de compreender, aceitar e assistir o doente mental, de forma adequada, antecede a criação ou a ampliação de serviços assistenciais.

Vale destacar que, em passado recente, os portadores de transtornos mentais eram enclausurados, vigiados constantemente, e, ainda, eram utilizados meios de persuasão e repressão para assegurar a ordem, particularmente no manicômio. No entanto, esse quadro mudou com o processo da Reforma Psiquiátrica, e o papel autoritário de vigiar, controlar e reprimir, principalmente delegados aos integrantes da equipe de enfermagem, de certa forma foi substituído por outro papel. $O$ enfermeiro que coordena e supervisiona toda essa equipe, passa a ter papel extremamente terapêutico, através do relacionamento interpessoal, sendo que, para isso, condutas autoritárias, restritivas e discriminadoras necessitam ser trabalhadas, pois atitudes voltadas a esses aspectos são muito diferentes de atitudes firmes, objetivas e terapêuticas, apoiadas no saber (PEDRÃO et al., 2003).

Preconceitos não trabalhados adequadamente podem se traduzir em atitudes negativas, principalmente se diretivos a portadores de transtornos mentais. 


\subsection{Atitudes}

Segundo Cavassa (2008), o termo atitude foi usado pela primeira vez por Thomas e Znaniecki, em pesquisa realizada em 1918, sobre camponeses poloneses emigrados para os Estados Unidos. O estudo desses sociólogos trata da identidade cultural e mudança social na comunidade imigrante polonesa nos Estados Unidos da América no início do século XX. Na sua obra, eles descrevem atitudes como a relação de dependência recíproca, entre a cultura e os indivíduos, e podem ser apreendidas se interpretar os problemas mediante a caracterização de valores sociais e atitudes.

São várias as definições citadas para atitude, mas, mesmo com as mais variadas interpretações, existem áreas que exibem concordância essencial, onde grande parte dos autores concordaria que uma atitude pode ser descrita como "predisposição" para responder, de maneira consistente, favorável ou desfavorável, em relação a um dado "objeto". Entretanto, existem dúvidas quanto à consistência das respostas, e, devido a isso, a maioria dos instrumentos utilizados para sua medida tem base na consistência avaliativa ou afetiva, sendo que uma pessoa, em diferentes situações, pode exibir diferentes comportamentos em relação a um dado objeto, mas a favorabilidade ou a desfavorabilidade expressa por esses comportamentos, mantém-se constante (FISHBEIN; AJZEN, 1975; RODRIGUES, 1992).

A palavra atitude existe na língua portuguesa não só como sinônimo de postura, modo de ter o corpo, mas, também, como sinônimo do significado de um propósito, norma de procedimento. A riqueza de seu significado faz dela um conceito como mediadora entre a forma de pensar dos indivíduos. As atitudes são inferidas e não diretamente observadas, mas, por outro lado, pressupõe-se que tenham ligação com os comportamentos.

Algumas citações clássicas acerca das atitudes.

"Por atitudes entendemos um processo de consciência individual que determina atividades reais ou possíveis do indivíduo no mundo social" (THOMAS; ZNAIECKI, 1918, p. 22).

"Atitude é um estado de preparação mental ou neural, organizado através da experiência e exercendo uma influência dinâmica sobre as respostas individuais a todos os objetos ou situações como se relaciona" (ALLPORT, 1935). 
"As atitudes são predisposições para responder a determinada classe de estímulos com determinada classe de respostas" (ROSENBERG; HOVLAND, 1960, p. 3).

A variável dependente nos estudos de dissonância cognitiva é, com muito poucas exceções, a afirmação de autodescrição de atitudes ou crenças. Mas como é que se adquirem esses comportamentos autodescritivos? A afirmação de determinada atitude pode ser vista como uma interferência a partir da observação do seu próprio comportamento e das variáveis situacionais em que ocorre. Dessa forma, as afirmações de um indivíduo são funcionalmente equivalentes às que qualquer observador exterior poderia fazer sobre ele. Quando a resposta à pergunta: gosta de pão de milho? É acho que sim, visto que estou sempre a comê-los, parece desnecessário invocar uma fonte de conhecimento pessoal privilegiada para dar conta da resposta (BEM, 1967).

Atitude face a um objeto consiste no conjunto de scripts relativos a esse objeto. Essa perspectiva combinada com uma teoria abrangente, acerca da formação e da seleção dos scripts, daria o significado funcional ao conceito de atitude que outras definições não possuem (ABELSON, 1976, p. 41).

As atitudes são vistas geralmente como predisposições comportamentais adquiridas, introduzidas na análise do comportamento social para dar conta das variações de comportamento em situações aparentemente iguais. Como estados de preparação latente para agir de determinada forma, representam os resíduos da experiência passada que orientam, enviesam ou, de qualquer outro modo, influenciam o comportamento. Por definição, as atitudes não podem ser medidas diretamente, mas têm de ser inferidas do comportamento (JASPARS, 1986, p. 22).

"Atitude é uma predisposição para responder de forma favorável ou desfavorável a um objeto, pessoa, instituição ou acontecimento" (AJZEN, 1988, p. 4).

BEM (1967) define atitude como o comportamento verbal através do qual as pessoas expressam as suas preferências e aversões. Abelson (1976) esquece a relação das atitudes com o comportamento e faz sua relação com as crenças e os valores individuais ou grupais. Jaspars (1986) coloca atitude em saber se são 
consideradas como respostas implícitas, predisposições para a ação, ou como filtros que moldam a percepção da realidade. As definições mais utilizadas de atitudes são, no entanto, as mais gerais e ecléticas como mostram Allport (1935) e Rosenberg e Hovland (1960).

As diferentes posições quanto ao conceito de atitude apresentam alguns pontos em comum: 1- as atitudes se referem às experiências, expressando 0 posicionamento de um indivíduo ou de um grupo, construído a partir da sua história e, portanto, com caráter aprendido; 2- as atitudes são sempre referidas a um objeto, quando se fala de atitude de um indivíduo, ou de um grupo social, refere-se, imediatamente, face a quê: atitude face ao aborto, atitude face ao desarmamento, atitude face à energia nuclear; 3- as atitudes incluem sempre uma dimensão avaliativa, as diferentes teorias acentuam mais ou menos ligações à cognição e ao comportamento, mas está sempre presente a dimensão afeto/avaliativa, isto é, atitude traduz sempre uma posição que, face a um determinado objeto social, pode ser expressa por gosto/não gosto, concordo/discordo.

Assim sendo, pode-se deduzir que diferentes pessoas podem ter atitudes diferentes face a um mesmo objeto, mas essa diversidade de posicionamento não deverá ser encarada como uma característica idiossincrática ou estável. As atitudes não nascem num vazio social, mas, pelo contrário, são fruto de interação social, de processo de comparação, identificação e diferenciação social que permitem situar a própria posição face à de outros, num determinado momento do tempo.

Outra forma de classificar o conceito de atitude é diferenciá-lo de outros construtos existentes na literatura que, de alguma forma apresentam semelhanças com atitudes. Assim, convém distinguir, em primeiro lugar, a atitude de outro construto hipotético que também se manifesta num conjunto largo de respostas observáveis: os traços de personalidade. A diferença reside no fato de as atitudes possuírem sempre um componente avaliativo a ser dirigido a um objeto específico (atitude negativa face ao aborto, por exemplo), enquanto os traços de personalidade não são necessariamente avaliativos, mas descrevem tendências de respostas num dado domínio que, sem especificarem o alvo do comportamento, se centram no indivíduo: tendência a ser sociável, a ser autoconfiante.

Outro construto limítrofe ao de atitude é o de crença. Tal como atitudes, se refere a um determinado objeto, mas, por crença entende-se a informação de que uma pessoa dispõe acerca do objeto, face ao qual se pode associar uma 
probabilidade de veracidade. As atitudes existem suportadas por crenças que constituem o seu componente cognitivo e racional. É através das crenças que se encontram os argumentos para, numa discussão, defender a própria posição atitudinal. Assim, a atitude seria a função avaliação das crenças à qual determinados objetos estão associados.

Valor é outro tipo de cognição que, tal como atitude, envolve explicação de preferências ou avaliações. Enquanto as atitudes se dirigem a um objeto, os valores são mais gerais e abstratos, transcendendo objetos e situações, e têm caráter normativo, que falta às atitudes (VALA; MONTEIRO, 2006).

\subsection{Transtorno mental}

Da mesma forma que ocorre com "atitude", é necessário definir "transtorno mental", tendo em vista constituir-se em um fenômeno, cuja maneira de entendimento varia amplamente, em diferentes culturas e comunidades, apresentando, ainda, variações com o passar do tempo (NUNNALY, 1961; RODRIGUES, 1992; PEDRÃO et al., 2005).

O transtorno mental permanece até hoje obscuro perante a medicina, ou seja, não há uma causa que realmente explique essa doença tão estigmatizante. No entanto, o adoecer psíquico é facilmente percebido, pois, em geral, são apresentados pelos indivíduos que adoecem comportamentos fora daqueles normalmente aceitos pela sociedade. Assim, não sendo entendida pela comunidade como doença de causa já bem conhecida, tem sua definição pela determinação cultural e de valores, e não apenas por fatores biológicos. Existindo, assim, o paradigma da exclusão social que se resume em isolamento dos doentes que não são aceitos dentro dos padrões habituais.

A estigmatização da loucura faz com que o doente perca a sua cidadania, sofra preconceitos e seja segregado da sociedade.

A história da doença mental, ou loucura, é relatada desde os primórdios da civilização, onde a pessoa considerada anormal era abandonada à sua própria sorte, para morrer de fome ou por ataque de animais. Hoje, é sabido que a doença mental, explicada por causas biológicas, psicológicas e sociais, necessita de assistência adequada, com a finalidade de ressocialização do doente e de apoio adequado para esse e para a família. A ressocialização ainda é difícil, pois, o 
transtorno mental, em, alguns casos, ainda é visto como transgressão de normas sociais, considerado uma desordem, não é tolerado e, portanto, segregado.

Muitas explicações sobrenaturais, antigamente, eram dadas para o transtorno mental, onde se tratava os doentes com métodos mágicos - religiosos, eram exorcizados e queimados. Na Renascença, predominavam três correntes: a orgânica, a psicológica e a mágica; no século XVII, houve o reconhecimento da influência psicológica das emoções sobre o corpo; na era do lluminismo, a doença passou a ser explicada mais pela razão, e os aspectos sobrenaturais perderam a força na influência da explicação da doença; mas, apesar de tudo isso, os doentes ainda eram excluídos da sociedade e eram aplicados, como forma de tratamento, purgativos e sangrias, tratados a chicote e morriam por falta de cuidados. No século XVIII, Pinel trouxe entendimento novo sobre o adoecimento mental que passou a ser considerado como distúrbio do sistema nervoso, e, então, recebeu a denominação de doença que precisava ser estudada (SPADINI; SOUZA, 2006).

Considerando os questionamentos que surgem quando há a necessidade de se definir "transtorno mental" e se diferentes populações compartilham, similarmente, tais definições, o estudo realizado pela World Federation of Mental Health (RODRIGUES, 1983) parece ser um dos mais amplos, por se tratar de investigação transcultural. Esse estudo mostra que a população, em geral, não distingue os vários tipos de transtornos mentais. Difere, apenas, o esgotamento nervoso do transtorno mental, classificando, como esgotamento nervoso, os transtornos originados do meio ambiente e que, submetidos a um tratamento de curta duração, teriam "cura". Como transtorno mental, sendo uma categoria mais complexa, afetaria o indivíduo em todos os níveis de desempenho, necessitaria de internações de longa duração, não proporcionando recuperação completa do paciente, pelo fato de sua personalidade já ter comprometimento permanente (HOOD, 1973).

Vale dizer que a tolerância da sociedade para com a pessoa portadora de transtorno mental é desproporcional, em sentido desfavorável, à real ameaça que essa pessoa é para a sociedade. Destaca-se, que, no contexto da Reforma Psiquiátrica e da Reabilitação Psicossocial, trabalhar a sociedade é extremamente importante, pois a aceitação do referido portador de transtorno mental e a compreensão na sua maneira de ser dispensaria, em grande parte, as referidas longas internações psiquiátricas. 
Ressalta-se que, se a recuperação completa não figura como uma realidade, um controle eficaz da sintomatologia psiquiátrica é plenamente possível, tanto devido ao grande avanço da psicofarmacologia (KAPLAN; SADOCK; GREEB, 1997) quanto às terapias psicológicas e sociais, de um modo geral, inclusive aquelas desenvolvidas nos Caps e, ainda, os diversos trabalhos e oficinas terapêticas, desenvolvidos em Organizações não-governamentais (ONGs), Associações de apoio ao portador de transtorno mental e outras Instituições que destinam seus objetivos a esses portadores tão discriminados, mesmo nos dias atuais, pela sociedade.

A população, de forma geral, exibe noções sobre o transtorno mental e o portador de transtorno mental do tipo racionalista (fatores psíquicos ou orgânicos) ou tradicionalista (cérebro fraco), sendo a primeira apresentada por indivíduos que desempenham atividades ocupacionais não manuais, e a última apresentada por indivíduos que desenvolvem atividades ocupacionais manuais. Estereótipos e preconceitos, como pessoa boba que não raciocina, agressiva, estranha, perigosa e que nunca mais sara, que traz problemas para a família e que tem que ficar no hospício são exibidos também pela população, sem correspondência real aos comportamentos que esses portadores emitem no meio social (AVANCl; MALAGUTI; PEDRÃO, 2002).

Até bem pouco tempo, a assistência ao portador de transtorno mental apresentava-se centrada nos hospitais psiquiátricos, locais da prática e do saber médico, cujo modelo de atenção restringia-se à internação e à medicalização, com base na apresentação dos sintomas demonstrados pelo referido portador de transtorno mental, excluindo-o dos vínculos, das interações e de tudo o que se configurava como elemento e produto de seu conhecimento. No modelo de atenção atual, a política assistencial vigente preconiza a diminuição da oferta de leitos hospitalares e a criação de serviços substitutivos de atenção à saúde mental, deslocando, assim, o seguimento e evolução dos tratamentos para o interstício das dinâmicas familiares, mobilizadas pela inclusão dos portadores de transtorno mental e também para a comunidade (AMARANTE, 1994). 


\subsection{Família}

A inclusão da família no tratamento à saúde mental começou a ser discutida no âmbito político e entre os profissionais de saúde da área, a partir da década de 1960, em alguns países europeus, e em 1980, no Brasil (AZEVEDO; MIRANDA; GAUDÊNCIO, 2009).

No primórdio da psiquiatria, a família não acompanhava o seu familiar portador de transtorno mental e permanecia totalmente alheia, sem participar ou se interessar pelo tratamento que era oferecido. Assim, ela se afastava dos cuidados, pois essa relação era subsidiada pelo paradigma da exclusão, sendo considerada uma das causas para o transtorno de seu familiar acometido. Contudo, se a família era afastada desse seu familiar, devido ao entendimento de que dificultava o tratamento do mesmo, hoje essa visão incluída, pelo entendimento de que o portador de transtorno mental necessita de tratamento digno, e que a participação da família é fundamental para sua recuperação (SPADINI; SOUZA, 2006).

A sociedade não está preparada para o desafio de acolher e cuidar das pessoas que adoecem mentalmente, com gravidade. As famílias se sentem paralisadas, fechadas em um universo tenso, reduzido, espesso. Carentes de informações qualificadas, perdidos e isolados, muitos se veem obrigados a cuidar do parente doente.

Com frequência, os familiares associam os sintomas da enfermidade à imagem de tragédias e catástrofes. Delírios e alucinações, comportamentos estranhos desestruturam as formas habituais de lidar com as situações do cotidiano.

Os familiares precisam de ajuda, e muita. O familiar culpado costuma mergulhar profundamente na pesquisa de eventuais erros do passado, buscando incessantemente explicações e sentidos que possam amenizar seu sofrimento. É muito difícil escapar dos efeitos aterradores dessa percepção negativa e estigmatizante, relacionada à doença mental.

É importante enfrentar o desafio de se tornar mais leve o peso das grandes frustrações e transformar a dor em matéria-prima de aprendizado, combustível para o processo de desenvolvimento.

$\mathrm{Na}$ sociedade moderna ocidental amar e cuidar dos filhos tornou-se tarefa extremamente complexa e difícil. São muitas as exigências e os deveres aos quais os pais estão submetidos no que diz respeito à educação e à formação das crianças 
até a idade adulta. Nos dias atuais, a família tem assumido a responsabilidade por qualquer anormalidade que possa romper a expectativa de criar filhos fortes, saudáveis, preparados para o mercado de trabalho e para viver em comunidade.

O surgimento de uma doença agrava drasticamente o quadro de insegurança e desconforto. Uma enfermidade mental gera muita tensão, estimula sentimentos de impotência e vitimização, alimenta amarguras. Nos casos em que a gravidade do quadro é maior e a duração dos sintomas se prolonga por muito tempo, os repetidos fracassos sociais dos pacientes, as dificuldades de comunicação e interação, os frequentes insucessos nos tratamentos produzem mais frustração e desespero e são um convite para progressivo isolamento da vida comunitária.

Quem são esses familiares? Como eles vivem? Quais são as suas dificuldades, suas questões, seus dilemas? Como lidam com os problemas? Não existe um padrão único e universal de familiar. Cada familiar é um familiar, cada família é uma família.

O século passado foi marcado pela transição dos valores familiares, deixando para trás o modelo que se tem em mente sempre que se refere à família: uma casa com quintal, pai, mãe e filhos vivendo juntos. Essa visão é correspondente ao ideal da família nuclear burguesa. A sociedade viveu algum tempo tentando alcançar o padrão desse modelo familiar. À medida que as famílias se afastaram dessa proposta, passaram a ser chamadas e avaliadas como desestruturadas ou incompletas. Ao se aceitar o modelo de família burguesa como norma e não como uma possibilidade de modelo construído historicamente, admitiu-se que deveria impor implicitamente seus valores, suas regras, suas crenças e padrões emocionais. Essa forma de perceber a questão da família ainda permanece, sendo reproduzida nos dias atuais. Essa concepção se apresenta invasivamente pela mídia, pelo discurso das instituições e dos profissionais, e é apresentada não só como a forma correta de viver em família, mas, também, como valor em si (OLIVEIRA; LOYOLA, 2004).

Existem muitas concepções de família que tentam explicar essa rede social complexa. Cada conceito é pautado em uma linha de pensamento diferente, e nem por isso menos importante.

O termo família origina-se do latim familius, que significa um grupo composto por um chefe ou senhor, seus servos e dependentes (PRADO, 1981). Para Ferreira (2004), família são as pessoas aparentadas que vivem, em geral, na mesma casa, 
particularmente o pai, a mãe e os filhos. São pessoas unidas por laços de parentesco, pelo sangue ou por aliança.

Hanson e Boyd (1996) utilizam uma definição para família, conforme a lei, que enfatiza relacionamentos através de laços sanguíneos, de adoção, de guarda ou de casamento. Outra definição é a biológica, que se centraliza na carga genéticobiológica comum.

Há também o conceito de família como unidade grupal, na qual se desenvolvem três tipos de relações pessoais: a primeira, caracterizada pelo casal (aliança) a segunda pelos pais e filhos (filiação) e a terceira e última pelos irmãos (consanguinidade). Tem como objetivo a preservação da espécie, a nutrição e a proteção de descendência, fornecendo condições para a aquisição de identidades pessoais, desenvolvendo, através dos tempos, várias funções: estéticas, éticas, religiosas e culturais, entre outras (OSÓRIO, 1996).

Para Elsen (1994), a família pode ser nuclear, composta de pai, mãe e filhos, e extensa ou ramificada, quando diferentes gerações estão incluídas. Considera também, como família as pessoas com as quais se mantêm laços afetivos, que podem apresentar ou não laços de consanguinidade. Um outro tipo de família é aquela composta apenas por amigos íntimos, com os quais não se há nenhuma consanguinidade. Na visão funcionalista, a família é conceituada como célula básica da sociedade, como um universo fechado, estático e de relações estritamente intrafamiliares. Na visão crítico-dialética, a família é o núcleo básico de produção e de reprodução social, unidade dinâmica e produtiva.

Diante das marcas de uma cultura globalizada, inscrita no campo simbólico e na construção dos saberes sociais, identifica-se a família enquanto um grupo que constitui um campo de relações entre pessoas que compartilham significados de suas experiências existenciais. Esse grupo atravessa os tempos passando por inúmeras transformações e críticas, sem se afastar, ao menos em tese, da responsabilidade e das exigências dos papéis socialmente atribuídos a ela de procriar e criar filhos saudáveis e preparados para assumir o mercado profissional e a vida em coletividade.

A assistência prestada aos portadores de transtornos mentais mostra que os familiares que procuram a ajuda e suporte dos serviços de saúde mental e de seus profissionais apresentam demandas das mais variadas ordens, dentre elas a dificuldade para lidar com as situações de crise vividas, com os conflitos familiares 
emergentes, com a culpa, com o pessimismo por não conseguir em ver saída dos problemas enfrentados, pelo isolamento social do qual ficam sujeitos, pelas dificuldades materiais da vida cotidiana, pelas complexidades do relacionamento com o portador de transtorno mental, sua expectativa frustrada de cura, bem como pelo desconhecimento da doença propriamente dita, algumas dentre tantas outras insatisfações (COLVERO; IDE; ROLIM, 2004).

A família é convocada a participar, efetivamente, do processo de reconstrução da dignidade do portador de sofrimento psíquico, ocupando lugar privilegiado nas discussões das políticas públicas em saúde mental, diante da Reforma Psiquiátrica. Ela representa o espaço indispensável à garantia da sobrevivência, desenvolvimento e proteção de seus membros, independente do arranjo familiar ou da forma como se estrutura. Cada família possui dinâmica de vida específica, dependente do processo de desenvolvimento socioeconômico e do impacto da ação do Estado, por meio de suas políticas econômicas, sociais e de saúde (AZEVEDO; MIRANDA; GAUDÊNCIO, 2009).

Esses familiares demarcam, assim, diferença a partir daquilo que para eles aparece como estranho, não esperado e não compreensível, no comportamento de seu familiar portador de transtorno mental, e o fazem fundamentados nos saberes historicamente acumulados e reiterados por meio de relações sociais. Saberes esses, sintetizados em antinomias, muitas vezes, maniqueístas, do normal e anormal, do bom e mal, do certo e errado, da saúde e doença, do comum e incomum, base racionalista do pensamento moderno (COLVERO; IDE; ROLIM, 2004).

\subsection{Grupos de autoajuda}

O grupo de autoajuda, self-help, de autossugestão, procura auxiliar as pessoa a resolver seus problema relacionados a eventos traumáticos, decorrentes do acometimento de doenças de natureza aguda e, em especial, crônica, aos transtornos aditivos, às incapacitações, a situações de causas existenciais e a traumas. São grupos homogêneos, no sentido de que seus participantes passam pelo mesmo sofrimento. Conceitua-se o grupo de auto ajuda baseado em sete critérios: são de apoio mútuo e educacional, a liderança vem do interior do grupo, reporta-se somente a um único evento desestruturador de vida, os membros do 
grupo participam voluntariamente, não tem interesses financeiros ou fins lucrativos, objetiva o crescimento pessoal dos integrantes, tem caráter anônimo e confidencial. São oito os princípios básicos do grupo de autoajuda: experiência compartilhada, educação, autoadministração, aceitação de responsabilidade por si próprio, objetivo único, participação voluntária, concordância na mudança pessoal, anonimato e confidência (ZIMERMAN; OSÓRIO, 1997).

Há três hipóteses básicas para compreender o funcionamento de autoajuda: homogeniedade, por mecanismo de identificação ocorre a coesão grupal, com o surgimento de alianças fraternais e a correspondente ação transformadora. A segunda hipótese é a chamada modelização, onde o mecanismo de auto ajuda será mais eficaz quanto maior for o compromisso emocional com paradigmas ou propostas explícitas de mudanças, ou de alguma ação determinada. A terceira e última hipótese básica, para compreender o funcionamento da autoajuda, é a confrontação, que é a necessidade de os membros do grupo se por em à prova, de confrontar em sua subjetividade com os dados objetivos, oriundos da realidade biológica, psicológica e social. Por isso, quanto maior foi o enfrentamento da realidade, maior a possibilidade de condutas saudáveis entre membros do grupo de autoajuda (ZIMERMAN; OSÓRIO, 1997).

Quanto à formação dos grupos de autoajuda, eles podem ser do tipo espontâneo ou incentivado por algum técnico, com liderança transitória ou eventual, ou com participação não diretiva, ou em disponibilidade para quando o grupo necessitar. O funcionamento homogêneo desses grupos é de característica autônoma (ZIMERMAN, 1993).

Caracterizando os grupos de autoajuda, é necessário citar os Alcoólicos Anônimos (AA) que nortearam todos os demais grupos com filosofia de irmandade. Essa filosofia se refere à informalidade nas reuniões, trocas de experiência entre seus membros e o uso da confrontalização, com consequente alerta para os prejuízos do consumo alcoólico e identificação dos mecanismos defensivos, usados para justificar a continuação do consumo. A filosofia da irmandade leva a atitude de autorreflexão, dentro de um clima no qual os membros participantes se sentem compreendidos, apoiados e respeitados pelos seus pares, com a melhora da auto estima.

Assim sendo, acredita-se que familiares de portadores de transtornos mentais que buscam informações acerca desses transtornos, causadores de grande 
sofrimento à pessoa da família acometida pelo transtorno mental, têm atitudes mais favoráveis frente a esses portadores e aos próprios transtornos mentais, o que thes confere mais chances de compreensão, aceitação e, consequentemente, cuidados adequados e possibilidades maiores de inserção do portador tanto na própria família quanto na sociedade, conforme preconiza a Reforma Psiquiátrica.

Dessa forma, as atividades oferecidas fora dos serviços de assistência psiquiátrica, por ONGs e associações, entre outros, se revelam de extrema importância, pois se constituem em verdadeiras modalidades terapêuticas com o compromisso de ocupar tanto as lacunas deixadas pelos referidos serviços quanto oferecer oportunidades de ocupação aos portadores de transtornos mentais que não conseguem vínculos empregatícios, ou ocupações, em outros locais, e, também, acolher os familiares de portadores desses transtornos, oferecendo oportunidades de participação em diversas situações que proporcionam conhecimento melhor dos transtornos em questão e formas adequadas de lidar com seus portadores.

Nesse contexto, os grupos de autoajuda, oferecidos por ONGs e associações, se apresentam como modalidade terapêutica de grande valor (ZIMERMAN; OSÓRIO, 1997). São grupos onde a mola propulsora das discussões está nos conteúdos revelados por quem já experimentou, ou ainda experimenta, a situação, o que pode ser traduzido nas trocas de experiências. Grupos desse tipo são parte das atividades oferecidas pelas ONGs e associações referidas e são extremamente importantes quando compostos por familiares de portadores de transtornos mentais, pois oferecem espaço para as referidas trocas de experiências e informações acerca dos referidos transtornos, levando a esses familiares chances de adquirirem maior e melhor conhecimento sobre os aspectos em questão e possibilidades concretas de terem atitudes mais positivas, frente aos transtornos mentais e seus portadores, levando a consequente melhor compreensão e aceitação dessas pessoas.

Partindo-se do princípio de que atitudes frente aos transtornos mentais e seus portadores, de forma geral, são passíveis de serem trabalhadas e modificadas, mesmo sendo necessário trabalho ao longo de grande período de tempo, pois se trata de trabalhar toda uma formação, conceitos e pré-conceitos e questões culturais, entre outros aspectos formadores da personalidade, e, acreditando que os grupos de autoajuda constituem-se em modalidade terapêutica importante no sentido de contribuir favoravelmente para a modificação das referidas atitudes, justifica-se a realização do presente estudo. 
Mostrar as atitudes, frente aos transtornos mentais, de familiares de portadores de transtornos mentais que frequentam um grupo de autoajuda.

Mostrar as atitudes, frente aos transtornos mentais, de familiares de portadores de transtornos mentais que não frequentam grupos dessa natureza.

Estudar comparativamente as atitudes frente aos transtornos mentais de familiares de portadores de transtornos mentais que frequentam um grupo de autoajuda com as atitudes, frente aos transtornos mentais, de familiares de portadores de transtornos mentais que não frequentam grupos dessa natureza. 


\subsection{Sujeitos e locais}

Participaram deste estudo 20 familiares de portadores de transtornos mentais, sendo 10 familiares que freqüentam o grupo de autoajuda organizado pela Associação de Apoio ao Psicótico (AAPSI) e 10 familiares que nunca participaram de grupo de autoajuda.

A AAPSI iniciou suas atividades no início do ano de 1998, ainda não estruturada como uma associação, vinculada a Associação Pró Saúde Mental sediada na cidade de São Paulo que oferecia, entre as suas atividades, os grupos de auto-ajuda denominados Psicóticos Anônimos. Após algum tempo de funcionamento, evoluiu, e, esta evolução, baseada principalmente na estrutura que adquiriu, possibilitou a sua transformação em Associação, isso ocorrendo em 31/07/2003, reconhecida no ano de 2005 como Utilidade Pública Municipal pela Lei 10328. A AAPSI, até então uma idéia em termos de uma associação independente, se fortaleceu e tornou-se autônoma, construindo, inclusive, sua própria sede. Sem vínculos religiosos, políticos ou de qualquer outra natureza, mantém-se através de doações. Com vida própria, elaborou seu cronograma de atividades a serem oferecidas ao portador de transtorno mental e seus familiares, todas absolutamente gratuitas e conduzidas por voluntários, que administram também a associação. Entre as atividades, estão os grupos de autoajuda, sendo em número de dois, um para os portadores de transtornos mentais e o outro para os seus familiares, amigos e parentes mais distantes que desejam participar. Tais grupos funcionam regularmente uma vez por semana, em salas distintas da AAPSI, com duração de duas horas.

A entidade está organizada em torno de dois objetivos: 1 - desenvolver ações de apoio ao psicótico e aos seus familiares; 2 - propugnar pela inserção do portador de transtorno mental na família e na sociedade, defendendo seus interesses e direitos. Em suma, a AAPSI é um projeto de apoio a este segmento da população proporcionando a inclusão social dos portadores de transtornos mentais, aliviando seu sofrimento e de seus familiares. É uma entidade sem fins lucrativos, única com essas características na cidade e região. É complementar aos benefícios oferecidos pelo sistema de saúde (atendimento clínico, psicológico, medicamentoso, internações, urgências e acompanhamento terapêutico), com funcionamento diário das 9 horas às 18 horas. 
Os 10 familiares que nunca participaram de grupo de autoajuda foram escolhidos aleatoriamente entre familiares que tiveram seus parentes internados em uma unidade de psiquiatria de um hospital geral, e, após a alta, encaminhados para seguimento em um grupo denominado GRUMA (Grupo em uso de Medicação Antipsicótica Atípica).

Como esses familiares tiveram contado com a unidade de psiquiatria e 0 GRUMA, é importante fazer uma breve caracterização desta unidade e deste grupo.

A unidade de psiquiatria foi criada em 1978 e recebe o nome de Unidade de Psiquiatria Prof. Dr. Luiz da Rocha Cerqueira, localizada no terceiro andar do Hospital das Clínicas da Faculdade de Medicina de Ribeirão Preto da Universidade de São Paulo. Possui 14 leitos para internação por período integral, sendo 8 femininos e 6 masculinos, e não consta em seu cronograma de atividades grupos com características de autoajuda, apenas grupos semanais para familiares, onde eles tem a oportunidade de oferecerem dados sobre o seu parente internado e receber retornos de sua evolução.

Durante o período de internação, o familiar pode também ser chamado para reuniões nucleares, que se constitui em uma reunião coordenada por uma assistente social com a participação de outros integrantes da equipe multiprofissional da Enfermaria de Psiquiatria, como o enfermeiro, o médico psiquiatra, o psicólogo e terapeuta ocupacional, entre outros. Nesta reunião, são tratados assuntos como a evolução do parente internado e possíveis dúvidas do tratamento.

Com relação ao GRUMA, trata-se de um grupo de pacientes que estiveram internados na unidade de psiquiatria e fazem uso de medicações antipsicóticas atípicas (em sua maioria a clozapina). Este grupo foi criado em 1998 devido ao grande número de pacientes fazendo o uso dessas medicações e necessitando de um acompanhamento mais próximo, principalmente após o período de internação, juntamente com seus familiares. As reuniões do GRUMA ocorrem às segundas feiras, no próprio terceiro andar do Hospital das Clínicas da Faculdade de Medicina de Ribeirão Preto da Universidade de São Paulo, com duração de uma hora, com um número de sete pacientes por reunião. O paciente participa apenas uma vez por mês, assim sendo, o grupo é diferente em cada segunda feira, isso para contemplar a demanda existente. Após a reunião, o paciente é atendido individualmente pelo médico psiquiatra. 
Assim, as caracterizações da unidade de psiquiatria e do GRUMA garantem, que os 10 familiares escolhidos aleatoriamente e inclusos na presente pesquisa, não tiveram contato com grupos de autoajuda.

\subsection{Instrumentos de coleta de dados}

Para a coleta de dados do presente estudo, foram utilizados dois instrumentos descritos a seguir.

O primeiro instrumento constituiu-se de um questionário (APÊNDICE A) com uma parte sobre os dados pessoais do familiar, sujeito do estudo, e a outra parte com perguntas abertas sobre sua proximidade e relação com a pessoa da família portadora de transtorno mental. Foi incluso neste instrumento o Critério de Classificação Econômica Brasil, que é um instrumento de segmentação econômica que utiliza o levantamento de características domiciliares (presença e quantidade de alguns ítens domiciliares de conforto e grau escolaridade do chefe de família) para diferenciar a população. O critério atribui pontos em função de cada característica domiciliar e realiza a soma destes pontos. É feita então uma correspondência entre faixas de pontuação do critério e estratos de classificação econômica definidos por A1, A2, B1, B2, C1, C2, D, E (CCEB, 2010).

O outro instrumento que foi utilizado constituiu-se de uma escala de atitudes denominada "Opiniões Sobre os Transtornos Mentais" (OTM) (ANEXO A), desenvolvida por Cohen e Struening (1962), traduzida e validada para a língua portuguesa e para o nosso meio por Rodrigues (1983) e, também, para o espanhol (RODRIGUES, 1992). É composta por 51 afirmações do tipo LIKERT e suas opções de respostas variam segundo uma sequência progressiva de seis pontos de concordância, desde "concordo totalmente" até "discordo totalmente". Essas afirmações estão agrupadas em sete fatores, que foram denominados por Rodrigues (1983, 1992) como mostra a seguir.

A. Autoritarismo - reflete a perspectiva de que a pessoa em sofrimento psíquico necessita ser isolada de outras pessoas, permanecendo sob portas trancadas e vigilância. Contém tanto o conceito da irrecuperabilidade pessoal e social quanto à ideia de sua periculosidade. 
B. Benevolência - traduz a visão de que a pessoa em sofrimento psíquico, devido à sua infelicidade, deve ser amparada através de protecionismo bondoso e paternalista, com base em cuidados, atenção pessoal e conforto material.

C. Ideologia de higiene mental - representa a ideia de que a pessoa em sofrimento psíquico é uma pessoa semelhante às pessoas normais, com diferenças quantitativas, porém não qualitativas. Podem desempenhar atividades especializadas e até cuidar de crianças.

D. Restrição social - traduz os transtornos mentais como uma espécie de defeito hereditário, completamente diferente de outras doenças ou transtornos, cujo portador pode contaminar a família e a sociedade, devendo, portanto, ser protegido através da restrição de seus direitos pessoais e sociais, mesmo após a hospitalização.

E. Etiologia interpessoal - explica os transtornos mentais como originários de vivências interpessoais, com maior ênfase à interação com figuras parentais.

F. Etiologia de esforço mental - reflete a ideia de que os transtornos mentais originam-se do excessivo "esforço cerebral", por meio do trabalho intelectual, exagerado, por pensar demais ou por ter pensamentos negativos.

G. Visão minoritária - traduz o conceito de que a pessoa em sofrimento psíquico, por ser muito diferente das pessoas tidas como normais, pode ser facilmente reconhecida em um agrupamento humano, principalmente pela sua aparência externa.

\subsection{Procedimentos}

\subsubsection{Procedimento ético}

O projeto de pesquisa foi enviado ao Comitê de Ética em Pesquisa Envolvendo Seres Humanos da Escola de Enfermagem de Ribeirão Preto da Universidade de São Paulo, seguindo rigorosamente as normas definidas pelo Conselho Nacional de Saúde do Ministério da Saúde, Resolução 196/96 (BRASIL, 1996), inclusive o termo de consentimento livre e esclarecido (APÊNDICE B), elaborado para esse fim. A apreciação e aprovação ocorreram em 19 de fevereiro de 2009 sob Protocolo no 0998/2009 (ANEXO B). 


\subsubsection{Aplicação dos instrumentos - Questionário e OTM}

Primeiramente, foi feito um rastreamento de todos os familiares cadastrados na AAPSI que participam ou participaram do grupo de auto-ajuda por ela oferecido. Esse rastreamento foi feito nos arquivos da Associação, onde estão as fichas com os dados de todos os seus participantes. Nesses arquivos, foram verificados 0 cadastro de 96 familiares. A partir desse número, estabeleceu-se um tempo mínimo de participação regular do familiar no grupo de autoajuda da referida Associação de no mínimo 5 anos para sua inclusão no estudo, tempo este considerado importante, no sentido do grupo ter exercido realmente uma influência suficiente para que o familiar utilizasse as informações provenientes das reuniões, principalmente no convívio com seu parente portador de transtorno mental.

Com este critério, verificou-se que era possível a inclusão de 20 familiares. No entanto, na busca por esses familiares, incluindo sua localização, convite e aceitação para a participação, foi possível a inclusão de 10, que aceitaram participar e assinaram o Termo de Consentimento Livre e Esclarecido. Assim, para aqueles que preferiram, a aplicabilidade dos instrumentos foi feita na própria sede da AAPSI, sendo um número de 5 , e, para os outros 5 , foi realizada visita em seu próprio domicilio, onde ocorreu a aplicabilidade dos instrumentos.

Para fins de comparação, buscou-se um número de familiares de portadores de transtornos mentais semelhante aquele do grupo de autoajuda da AAPSI, mas, agora, com a garantia de que nunca haviam participado de grupos de autoajuda. Assim, esses familiares foram escolhidos de forma aleatória no ambulatório de pósalta psiquiátrica do Hospital das Clínicas da Faculdade de Medicina de Ribeirão Preto, nos retornos de seus parentes egressos da Unidade de Psiquiatria Prof. Dr. Luiz da Rocha Cerqueira antes caracterizada e do GRUMA, também anteriormente caracterizado. Então, após a escolha dos 10 familiares, eles foram convidados a participar da pesquisa, e, com o aceite, assinaram o Termo de Consentimento Livre e Esclarecido. A aplicabilidade dos instrumentos ocorreu em uma sala adequada, no próprio local da reunião do GRUMA.

Destaca-se que o desenvolvimento de todo o procedimento foi realizado pela própria pesquisadora, que pôde também, no momento, esclarecer possíveis dúvidas dos familiares participantes e fazer esclarecimentos. 


\subsubsection{Análise dos resultados}

Os questionários foram analisados individualmente, com leitura aprofundada de todas as respostas e síntese dos conteúdos. Através das sínteses dos referidos conteúdos, a análise ocorreu de forma qualitativa descritiva com base no referencial teórico de Minayo (2004).

Relativo à OTM, após a sua aplicabilidade os dados foram transferidos para um banco criado para este fim, na forma de dupla digitação, conferência e correções, evitando, assim, erros na referida transferência.

Para contagem dos pontos obtidos com a aplicação da OTM, foi usado procedimento idêntico ao de Rodrigues (1983). Sendo assim, foram utilizadas as fórmulas estabelecidas por Struening e Cohen (1963), originando-se, dessa forma, os escores fatoriais brutos para cada familiar, nos sete fatores dessa escala.

Por não ser possível trabalhar com esses escores fatoriais, tendo em vista que o número de itens é diferente para cada fator, foi necessário transformar para um sistema que permitia comparação padrão. Para isso, o sistema "Sten" (escores Sten) se mostra adequado, pois proporciona comparação padrão entre os fatores da escala referida, com variação entre 1 e 10, média de 5,5 e desvio padrão igual a 0,5 (CANFIELD, 1951). As vantagens da utilização desse sistema foram amplamente discutidas por Lyman (1963).

Dessa forma, foi possível a análise dos resultados através dos escores obtidos pelos sujeitos deste estudo, para cada fator da OTM, de forma quantitativa, através de cálculos estatísticos com a importação dos dados do programa Eplnfo 6 para o programa SPSS, utilizando o teste não-paramétrico de Mann-Whitney $U$, para obter a significância estatística. A escolha pelo teste de Mann-Whitney $U$ foi por ser adequado ao número de indivíduos do estudo. 
Os resultados são apresentados em duas partes, sendo a primeira proveniente das respostas ao questionário, incluindo a classificação econômica, e, a segunda, proveniente das respostas à OTM.

\subsection{Dados obtidos através do questionário e classificação econômica}

O número de familiares entrevistados foi de 20 divididos em dois grupos, sendo um grupo com 10 familiares que participam regularmente de um grupo de autoajuda há 5 anos ou mais (denominado Grupo 1) e outro grupo, também com 10 familiares que não participam e nunca participaram de grupo de autoajuda (denominado Grupo 2). Os dados pessoais dos familiares participantes do estudo são apresentados no Quadro 1 a seguir.

\begin{tabular}{|c|c|c|}
\hline & Grupo 1 & Grupo 2 \\
\hline \multicolumn{3}{|c|}{ Faixa Etária } \\
\hline $45-50$ anos & 0 & 2 \\
\hline $51-60$ anos & 4 & 6 \\
\hline $61-70$ anos & 6 & 2 \\
\hline \multicolumn{3}{|c|}{ Sexo } \\
\hline Masculino & 1 & 2 \\
\hline Feminino & 9 & 8 \\
\hline \multicolumn{3}{|c|}{ Estado Civil } \\
\hline Casado & 7 & 7 \\
\hline Viúvo & 2 & 2 \\
\hline Divorciado & 1 & 1 \\
\hline \multicolumn{3}{|c|}{ Religião } \\
\hline Católico & 9 & 8 \\
\hline Espírito & 1 & 0 \\
\hline Evangélico & 0 & 2 \\
\hline A1 & Classificação Econômica \\
\hline A2 & 1 & 0 \\
\hline B1 & 2 & 0 \\
\hline B2 & 5 & 1 \\
\hline C1 & 1 & 2 \\
\hline . & 1 & \\
\hline
\end{tabular}

Quadro 1 - Dados pessoais dos sujeitos do estudo.

No Grupo 1 os familiares relataram os inícios dos transtornos mentais e tratamentos há mais de 10 anos. No Grupo 2, os inícios dos transtornos mentais 
relatados pelos familiares e tratamentos foram de 5 anos ou mais como mostra 0 Quadro 2.

\begin{tabular}{|c|c|c|c|c|}
\hline & \multicolumn{2}{|c|}{ Início dos Transtornos Mentais } & \multicolumn{2}{c|}{ Início dos Tratamentos } \\
\hline Período & Grupo 1 & Grupo 2 & Grupo 1 & Grupo 2 \\
\hline 5-9 anos & 0 & 3 & 0 & 3 \\
\hline $10-15$ anos & 6 & 2 & 6 & 2 \\
\hline $16-20$ anos & 3 & 3 & 3 & 3 \\
\hline $21-25$ anos & 0 & 0 & 0 & 0 \\
\hline $26-30$ anos & 1 & 2 & 1 & 2 \\
\hline
\end{tabular}

Quadro 2 - Início dos transtornos mentais e dos tratamentos nos grupos 1 e 2.

Alguns dados obtidos através do questionário optou-se por apresentá-los de forma descritiva. Assim, relativo ao grau de parentesco com o portador de transtorno mental, os participantes do estudo se constituíram em pais e irmãos. Em ambos os Grupos, a maioria dos familiares constituiu-se de mães, perfazendo um total de $80 \%$ nos grupos 1 e 2, e pais, que se constituíram em 10\% também nos grupos 1 e 2 . Com relação aos irmãos, no grupo 1 foram 10\% irmãs, e, no grupo 2, foram 10\% irmãos.

Em ambos os grupos, a maioria dos familiares mora junto com os portadores, sendo $70 \%$ no Grupo 1 e 90\% no Grupo 2.

No grupo 1,70\% dos familiares afirmaram ter contado com outro cuidador, porém, $50 \%$ afirmaram que sempre dividiram os cuidados, levando ao entendimento de que nem sempre houve a participação de outro cuidador em todos os casos. Já no Grupo 2, $90 \%$ dos familiares afirmaram ter outro cuidador e os mesmos $90 \%$ sempre dividiram os cuidados.

No Grupo 1, 90\% dos familiares possuem atividades profissionais fora do lar, e, no Grupo 2, apenas 40\% possuem essas mesmas atividades.

No Grupo 1, 30\% afirmaram que o cuidar atrapalha sua vida hoje em algum aspecto, e que, no passado, atrapalhava muito mais, isso relatado por $90 \%$ dos sujeitos. No Grupo 2, apenas $10 \%$ afirmaram que o cuidado atrapalha sua vida hoje e que, no passado, também atrapalhava mais, isso relatado por $30 \%$ dos familiares.

O transtorno mental com maior incidência nos grupos foi a esquizofrenia, sendo no Grupo 1 de 60\% e no Grupo 2 de 100\%. Outro transtorno mental evidenciado no estudo foi o transtorno afetivo bipolar, com incidência no Grupo 1 de $40 \%$. 


\subsection{Resultados da OTM}

Os resultados provenientes da aplicabilidade da OTM estão apresentados separadamente para os dois grupos, sendo o Grupo 1 dos familiares que participaram de grupo de autoajuda e o Grupo 2 dos familiares que não participaram de grupos dessa natureza. Posteriormente, serão apresentadas as comparações dos resultados dos grupos.

Relativo às atitudes dos familiares, frente aos transtornos mentais e seus portadores, do Grupo 1, o escore Sten médio para os sete fatores da OTM foram os seguintes: Autoritarismo 6,7; Benevolência 6,5; Ideologia de Higiene Mental 4,5; Restrição Social 7,5; Etiologia Interpessoal 3,9; Etiologia do Esforço Mental 6; Visão Minoritária 5,6; conforme mostra o Gráfico 1, a seguir.

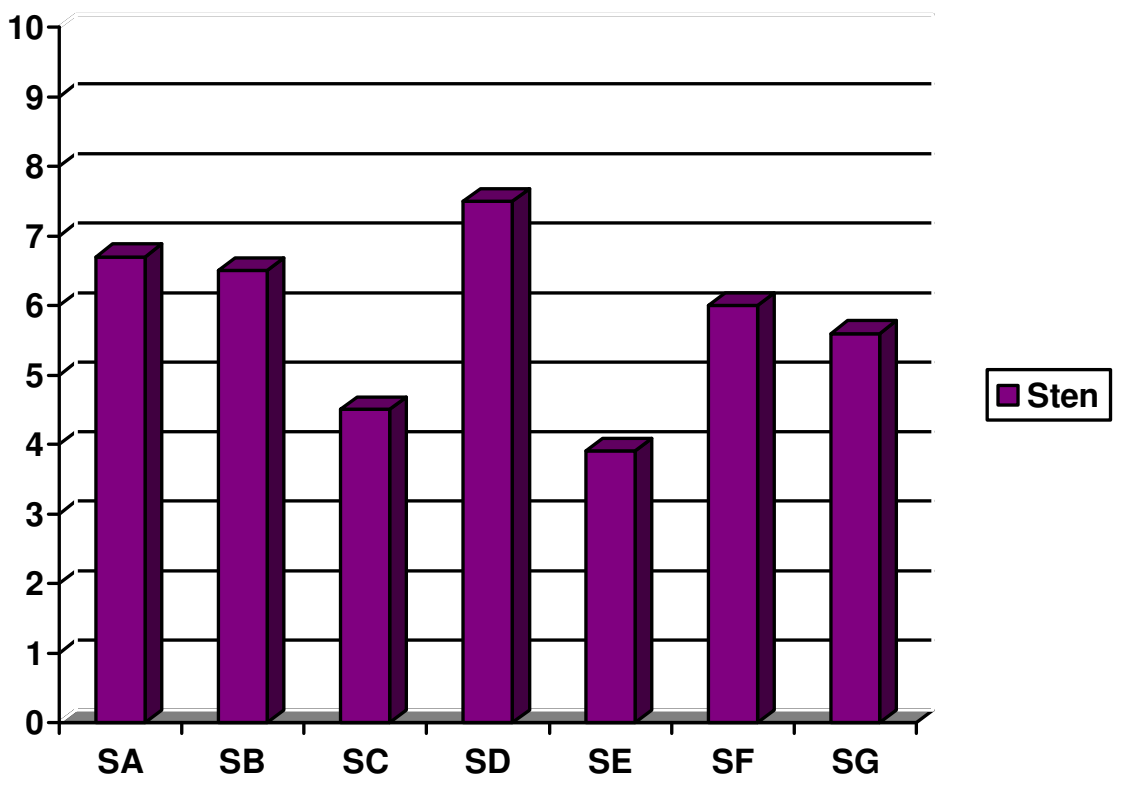

Gráfico 1 - Escores Sten médios para os sete fatores da OTM do Grupo 1.

Em relação às atitudes dos familiares, frente aos transtornos mentais e seus portadores do Grupo 2, o escore Sten médio para os sete fatores da OTM foram os seguintes: Autoritarismo 8,3; Benevolência 5; Ideologia de Higiene Mental 3,3; Restrição Social 7,4; Etiologia Interpessoal 3,4; Etiologia do Esforço Mental 6,8; Visão Minoritária 6,5; conforme mostra o Gráfico 2, a seguir. 


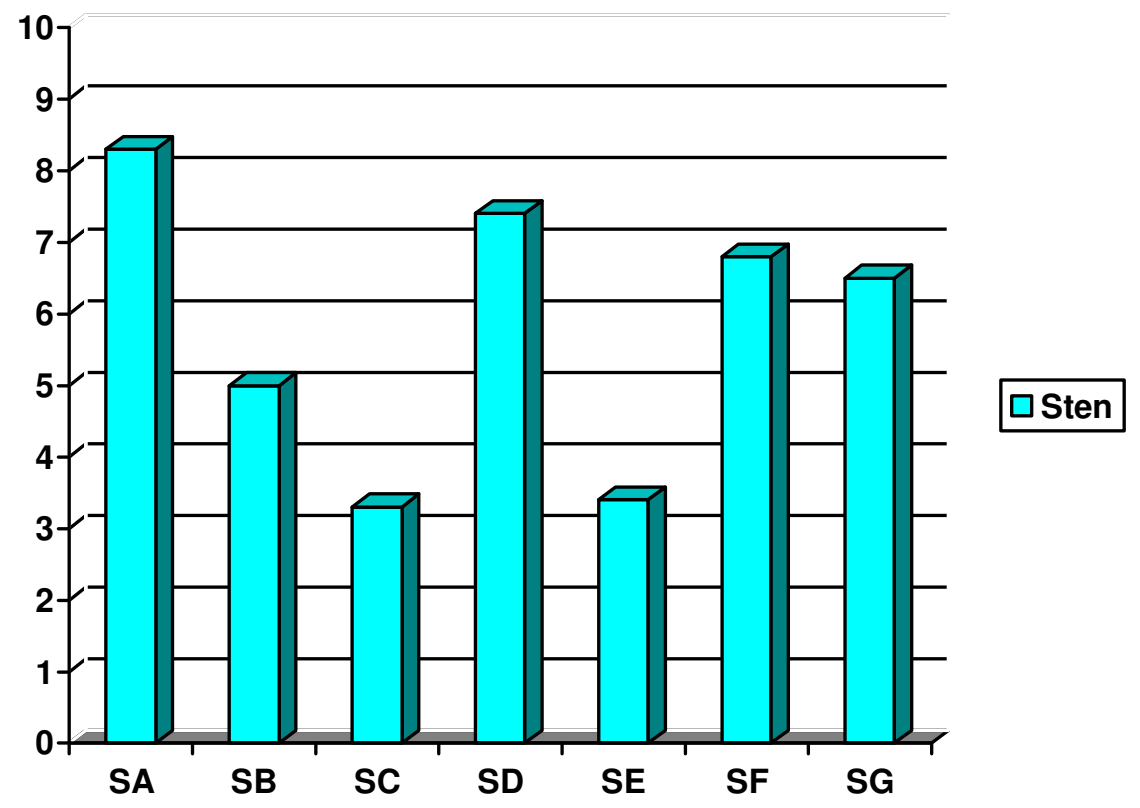

Gráfico 2 - Escores Sten médios para os sete fatores da OTM do Grupo 2.

A comparação das atitudes dos familiares, frente aos transtornos mentais e seus portadores do Grupo 1 com o Grupo 2, está apresentada no Gráfico 3, a seguir.

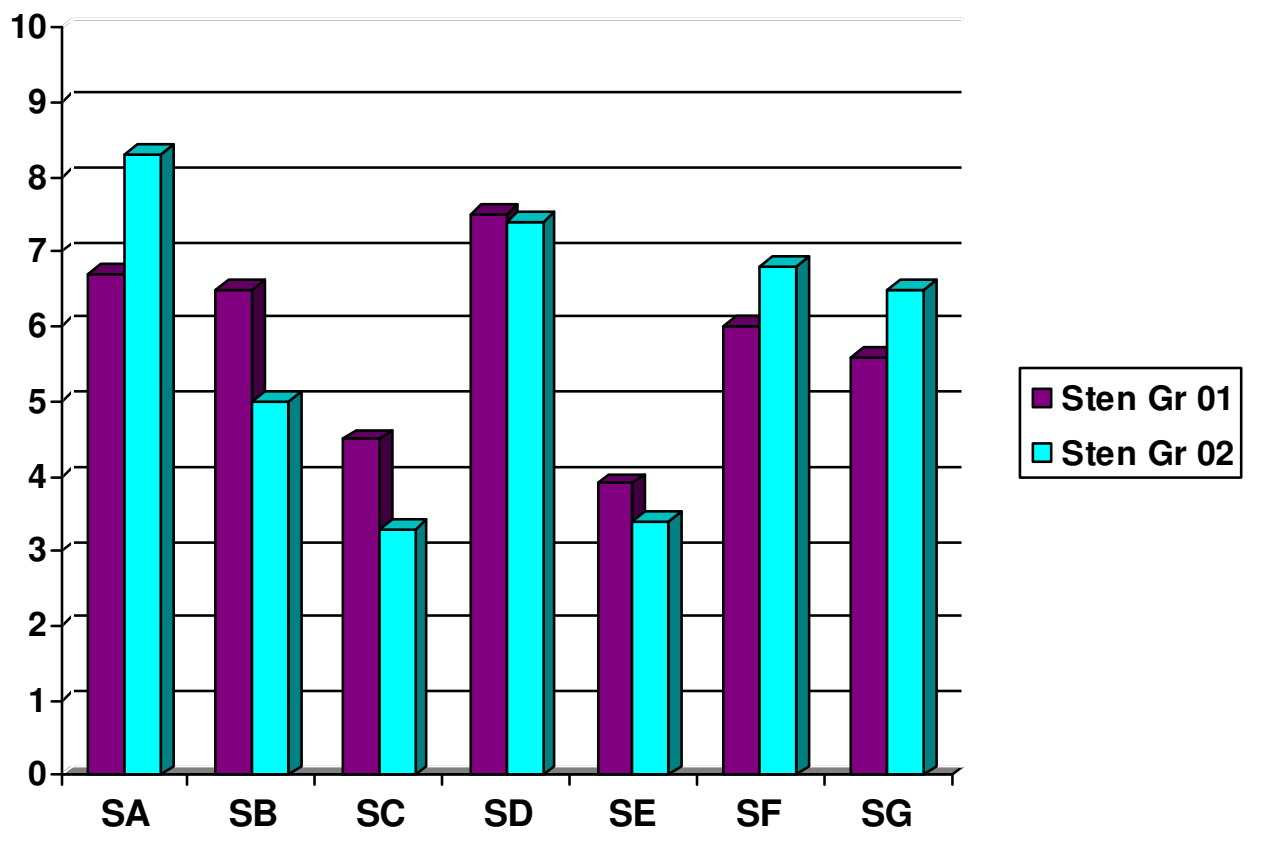

Gráfico 3 - Escores Sten médios comparativos para os sete fatores da OTM do Grupo 1 e do Grupo 2. 
Comparando os resultados obtidos com a aplicabilidade da OTM nos Grupos 1 e 2, pelo teste de Mann-Whitney $U$, observa-se que três fatores: Autoritarismo, Benevolência e Ideologia da Higiene Mental, mostraram diferenças estatisticamente significantes com a menor que 10\%, como mostra a Tabela 1, apresentada a seguir.

Tabela 1 - Comparação dos resultados obtidos com a aplicabilidade da OTM nos Grupos 1 e 2 pelo teste de Mann-Whitney U.

\begin{tabular}{clllllll}
\hline TESTE & SA & SB & SC & SD & SE & SF & SG \\
\hline $\begin{array}{c}\text { Mann- } \\
\text { Whitney U }\end{array}$ & 26,500 & 19,500 & 26,500 & 47,000 & 47,500 & 39,000 & 37,500 \\
$\begin{array}{c}\text { Z } \\
\text { Asymp. Sig. } \\
\text { (2-tailed) }\end{array}$ & $-1,802$ & $-2,479$ & $-1,821$ &,- 231 &,- 194 &,- 843 &,- 974 \\
\hline
\end{tabular}


Discussão | $\mathbf{3 8}$

5 DISCUSSÃo 
Estudar as atitudes de familiares de portadores de transtornos mentais, frente a esses transtornos, é particularmente importante, pois essas atitudes certamente interferem no modo de compreender as reações que o referido portador desses transtornos têm frente às diversas situações cotidianas, e, consequentemente, no modo de lidar com essas reações.

Assim sendo, na busca por instrumento que facilitasse o estudo das referidas atitudes, foi encontrada a OTM, escala desenvolvida na década de 1960, mundialmente utilizada, traduzida e validada para o nosso meio, na década de 1980, mostrando-se, ainda, extremamente atual e muito utilizada. Dessa forma, a OTM mostrou-se adequada às pretensões do presente estudo, da mesma forma como em diversos outros estudos na atualidade (ABREU, 2010; ARVANITI et al., 2008; HAMAIDEH; MUDALLAL, 2009).

A verificação das referidas atitudes em dois grupos distintos também foi oportuno, pois, com isso, foi possível obter-se dados comparativos de familiares de um grupo que troca informações sobre os transtornos mentais e como lidar com as pessoas que possuem esses diagnósticos, com outras, que não têm facilidade para obter essas mesmas informações, mesmo participando de reuniões de grupos.

O número de sujeitos do presente estudo foi direcionado pela possibilidade de inclusão de sujeitos no Grupo 1, que teve número de 10 participantes. Esse número pode ser considerado relativamente pequeno frente às possibilidades e oportunidades que os familiares têm de participar de grupos de autoajuda com as características antes definidas, mas, de um modo geral, a participação desses familiares se limitam aos momentos em que o seu parente, portador de transtorno mental, está em fase muito difícil e de grande produtividade de sintomas, o que é chamado de fase aguda ou o surto dos referidos transtornos, e se afastam do grupo quando há melhoras ou o controle dos sintomas. Assim sendo, mesmo com aproximadamente 100 familiares cadastrados no grupo de autoajuda da AAPSI, apenas os 10 familiares inclusos reuniram as condições para tal inclusão. Portanto, o número também de 10 familiares do outro grupo foi estabelecido a partir da possibilidade de inclusão dos 10 familiares do grupo de autoajuda da AAPSI, conforme referido.

No que diz respeito às características gerais dos familiares sujeitos do estudo, no Grupo 1, conforme mostra o Quadro 1, a maioria está acima dos 60 anos, sendo $60 \%$ desses familiares pertencentes a essa faixa etária, mas $100 \%$ estão na faixa 
etária acima dos 50 anos. No Grupo 2, a maioria está abaixo dos 60 anos, mas acima dos 50 anos, com $80 \%$ dos familiares nessa faixa etária. Portanto, destaca-se o fato de que, em ambos os grupos, os familiares, certamente também cuidadores por serem mães, inclusive, pertencerem a faixa etária mais avançada, mostrando que é comum em nossa sociedade cuidadores idosos, apesar de esse ser trabalho muito cansativo e desgastante, considerando-se, ainda, os problemas vivenciais do processo de envelhecimento normal como depressão, desgaste fisiológico e problemas crônico-degenerativos (MARQUES, 2000).

O estudo demonstrou predomínio do gênero feminino em ambos os grupos, com $90 \%$ no Grupo 1 e $80 \%$ no Grupo 2. O fato deste estudo apontar para maioria de cuidadores do gênero feminino mostra, segundo Nakatani et al. (2003), que a sociedade, através de sua cultura, imputa o papel de cuidar à mulher, seja ela a mãe, a cônjuge ou a irmã. Essa atividade consiste em algo cultural e socialmente definido para o ser mulher, que, normalmente, tem filhos, marido, atividades domésticas, além de, muitas vezes, trabalhar fora do lar. Muraro e Boff (2002) descreveram a forte e histórica relação entre fêmeas e prole como origem do cuidado e afetividade da espécie humana. Assim, as raízes históricas e culturais do cuidar podem explicar a expressiva presença feminina observada entre os cuidadores, neste estudo.

Dentre os familiares não há diferença quanto ao estado civil. Nos dois grupos, a maioria apresentou-se como casados, representados por $70 \%$ dos participantes. Os demais, $20 \%$ apresentaram-se como viúvos e $10 \%$ separados, dados esses, que se assemelham a outros estudos (HENZ, 2011; PIMENTA, 2009; RIBEIRO et al., 2008) nos quais a maioria dos cuidadores apresenta-se como casados.

Com relação à religião, em ambos os grupos a maioria apresentava-se como católica, sendo de 90\% no Grupo 1 e 80\% no Grupo 2. Os demais, se apresentaram como espíritas no Grupo 1 (10\%) e evangélicos no Grupo 2 (20\%). A religião tornase uma forma de amparo e de apoio, porque a oração proporciona momentos de tranquilidade e de bem-estar para os cuidadores. Enquanto recursos eficazes de enfrentamento, a religiosidade e a espiritualidade atuam como mediadores na percepção de ônus ou benefícios, decorrentes da tarefa de cuidar (NERI; SOMMERHALDER, 2002; SOCCI, 2006), amenizando o impacto negativo de certos eventos. 
$\mathrm{Na}$ análise da condição econômica, seguindo os Critérios de Classificação Econômica Brasil (CCEB, 2010), no presente estudo, foi possível classificar os familiares participantes nas categorias $A 1, A 2, B 1, B 2$ e C1, sendo as classes C2, D e E não evidenciadas. Foi observada melhor condição econômica no Grupo 1, sendo $80 \%$ dos familiares pertencentes às classes A1, A2 e B1. No Grupo 2, foi observada condição econômica menos favorecida, sendo $90 \%$ dos familiares pertencentes às classes B2 e C1. É importante ressaltar que o critério de classificação considera o domicílio (posse de bens e a escolaridade), onde a pessoa reside, e não a renda individual. Os familiares do Grupo 1, usufruindo de uma condição econômica mais vantajosa que o Grupo 2, contam, ainda, com mais equipamentos em seus domicílios, como número maior de televisores, videocassetes, e DVDs entre outros, o que pode favorecer a busca de mais recursos didáticos. Além disso, podem ser estimulados na busca de conhecimentos sobre os transtornos mentais, pois vivem em ambientes cujos chefes de família, detectados na aplicação do CCEB, são também mais instruídos (RIBEIRO et al., 2008).

Sobre o grau de parentesco dos familiares com os seus parentes portadores de transtornos mentais, em sua maioria, era composta por mães em ambos os grupos (80\%), o que vai de encontro com outros estudos (HENZ, 2011; PIMENTA, 2009; RIBEIRO et al., 2008). Mães de diferentes classes sociais consideraram que ser mãe é ser a responsável pelos filhos e existe uma atribuição no sentido de maternidade que se mostra comum entre as mulheres de diferentes classes sociais: o cuidado e a educação dos filhos, destacando que esses valores sempre foram atribuídos à figura feminina desde o tempo do Brasil Colônia (ALMEIDA, 2007).

Quanto ao início dos transtornos mentais, no Grupo 1, os portadores desses transtornos se apresentaram com tempo maior de diagnóstico confirmado, todos acima de 10 anos. No Grupo 2, o tempo de início do transtorno foi menor, com diagnóstico confirmado acima de 5 anos. Em ambos os grupos o tempo maior de convívio com o transtorno mental foi de 30 anos. O início do tratamento do transtorno mental, em ambos os grupos, foi imediatamente após o surgimento do referido transtorno e isso se mostra particularmente importante pelo fato de que, quando diagnosticado precocemente, há maiores possibilidades de intervenções terapêuticas mais adequadas e prognósticos mais favoráveis (MIRANDA et al., 2008). 
Nos dois grupos, a incidência maior do transtorno mental foi a esquizofrenia com 60\% no Grupo 1 e 100\% no Grupo 2. Partindo do princípio de que a esquizofrenia é o transtorno mental que tem o pior prognóstico, entre os transtornos mentais, e o que causa mais perdas e prejuízos, de um modo geral (JUCÁ, 2005), é de se supor que os familiares que têm os seus parentes portadores desses transtornos procurem mais ajuda para melhorar a qualidades de vida desses seus parentes, confirmando, assim, a busca pelo grupo de autoajuda. No Grupo 2, 0 diagnóstico de esquizofrenia em todos os parentes dos familiares inclusos aleatoriamente no estudo deu-se pelo fato de serem participantes de um grupo de usuários de medicações antipsicóticas atípicas em pós-alta hospitalar (GRUMA), onde todos os usuários têm diagnóstico de esquizofrenia. Importante lembrar que o maior número de internações psiquiátricas é de portadores de esquizofrenia (BRASIL, 2011).

Em ambos os Grupos a maioria dos familiares mora junto com os portadores, sendo 70\% no Grupo 1 e 90\% no Grupo 2. Com a implantação da política de desinstitucionalização, a família passou a ser responsável pelo cuidado do paciente, com mães, pais e irmãos morando com eles para oferecer os cuidados como encontrado na maioria dos estudos (GOES, 2007; GOES; CARMO, 2005; SILVA; SADIGURSKY, 2008; SOARES; MUNARI, 2007).

Estudo realizado por Goes e Carmo (2005) mostra que as cuidadoras de portadores de transtornos mentais trouxeram uma realidade comum de solidão, com a responsabilidade sobre a pessoa portadora de transtorno mental, deixando evidente que nem sempre contaram com ajuda direta de outro membro da família no cuidado. No Grupo 1,70\% dos familiares afirmaram contar com outro cuidador atualmente, porém, nem sempre foi assim, onde, no passado, 50\% deles afirmaram que sempre dividiram os cuidados. Já no Grupo 2, esse número mostrou-se mais expressivo, sendo que $90 \%$ dos familiares afirmaram ter outro cuidador, atualmente, e os mesmos $90 \%$ sempre dividiram os cuidados, também, em anos anteriores. Isso mostra que os familiares que participam do grupo de autoajuda, oferecido pela AAPSI, permanecem mais próximos de seus parentes portadores de transtornos mentais, trazendo para si os cuidados, de modo geral, nos dias atuais, ou mesmo não sendo necessárias buscas de outras pessoas para tal cuidado, pois, possivelmente, esses parentes de portadores de transtornos mentais são mais autônomos, partindo do princípio de que os parentes dos familiares do outro grupo, 
ou Grupo 2, são egressos de internação por período integral, e, provavelmente, ainda sem grau de autonomia suficiente para a condição total de autocuidado.

O cuidar do portador de transtornos mentais nem sempre é fácil. Segundo Silva e Sadigursky (2008), lidar com o portador e a relação com ele é, muitas vezes, fator de incomodo e de empecilho para a vida familiar harmoniosa. A convivência com alguém que, por muitas vezes, fica acordado durante uma noite inteira, conversando sozinho ou falando coisas que só faz sentido para ele mesmo, contribui para que o clima dentro de casa se torne alterado e pesado. O cuidar, segundo os familiares participantes deste estudo, atrapalha sua vida hoje em algum aspecto, isso apareceu em 30\% no Grupo 1 e 10\% no Grupo 2, porém, o número é maior quando se refere ao passado, onde o aspecto atrapalhar era presente em $90 \%$ no Grupo 1 e 30\% no Grupo 2. Isso pode ser relacionado à condição socioeconômica, melhor no Grupo 1, e, onde, o aspecto atrapalhar fica mais evidente, pois, certamente, essa condição mais privilegiada leva a possibilidades maiores de lazer, viagens e reuniões sociais, entre outros, certamente menos presente no Grupo 2. Independente da relação do aspecto atrapalhar com o cotidiano dos familiares, de um modo geral, destaca-se que as preocupações com o parente portador de transtorno mental são constantes e levam a sobressaltos e cansaço, fazendo parte do cotidiano desses familiares, ultrapassando o cuidado físico, chegando ao ponto máximo de responsabilidade a questão de mantê-lo sob vigilância e proteção (GOES; CARMO, 2005).

No Grupo 1, 90\% dos familiares possuem atividades profissionais fora do lar, já no Grupo 2, apenas 40\% possuem essas atividades. Isso ressalta as colocações feitas anteriormente, onde, realmente, no Grupo 1, o grau de autonomia dos parentes dos familiares participantes do presente estudo tem todo o indicativo de ser maior, e, ao contrário, no Grupo 2, a situação é inversa, ou seja, os familiares ficam mais no lar, oferecendo-se ao cuidado, contando, ainda, com mais ajuda, provavelmente, também pelas condições já descritas. Isso vai ao encontro a estudos que mostram que a maioria das cuidadoras dos portadores de transtornos mentais não exercem outras atividades além do cuidado, sendo a maioria mães e de classe econômicas mais baixa, assim apresentam-se os familiares do Grupo 2 (GOES; CARMO 2005; SILVA; SADIGURSKY, 2008).

Quanto às atitudes dos familiares dos portadores de transtornos mentais, frente aos transtornos mentais e seus portadores, no Grupo 1 observa-se que os 
fatores A (Autoritarismo), B (Benevolência) e D (Restrição Social) apresentaram os maiores escores médios, com escore Sten de 6,7; 6,5 e 7,5; respectivamente. Esses escores podem ser entendidos como elevados, partindo do princípio de que esses familiares participam de grupo que troca experiências constantemente sobre o convívio com o seu parente portador de transtorno mental, e que poderia apresentar atitudes mais positivas nesses aspectos, embora possam ser considerados comportamentos extremamente difíceis de serem modificados, apenas com participações em modalidades terapêuticas que trabalham em sentido mais geral e não com tanta proximidade e avaliações, mais possíveis em modalidades terapêuticas mais centradas. No Grupo 2, os fatores A (Autoritarismo) e D (Restrição Social) também apresentaram os maiores escores médios com escores Sten de 8,3 e 7,4; respectivamente, juntando-se a esses dois fatores o fator $F$ (Etiologia de Esforço Mental) com escore sten 6,8. Observando comparativamente os escores Sten entre os grupos, percebe-se que o Grupo 1 é menos autoritário e mais benevolente, apresentando significância estatística como mostra a Tabela 1 e não há diferença na avaliação da restrição social.

O Autoritarismo reflete a perspectiva de que a pessoa com transtorno mental necessita ser isolada de outras pessoas, permanecendo sob portas trancadas e vigilância. Contém tanto o conceito da irrecuperabilidade pessoal e social quanto a ideia de sua periculosidade. A Benevolência traduz a visão de que a pessoa com diagnóstico de transtorno mental, devido à sua infelicidade, deve ser amparada através de protecionismo bondoso e paternalista, com base em cuidados, atenção pessoal e conforto material. A Restrição Social traduz os transtornos mentais como espécie de defeito hereditário, completamente diferente de outras doenças ou transtornos, cujo portador pode contaminar a família e a sociedade, devendo, portanto, ser protegido através da restrição de seus direitos pessoais e sociais, mesmo após a hospitalização (RODRIGUES, 1983).

O Autoritarismo constitui um traço de personalidade básico, e, portanto, menos passível de ser modificado (ABREU, 2010), o que pode explicar o alto escore desses familiares em ambos os Grupos, particularmente naquele que participa de grupos de autoajuda há mais de 5 anos. A atitude de Benevolência, entendida então como atitude caritativa (RODRIGUES, 1983), é dirigida ao portador de transtorno mental pelo entendimento de seus comportamentos infantis e que precisa ser vigiado por guarda compassiva, levando também à restrição de seus direitos como 
cidadão (CORRIGAN et al., 2001), o que, consequentemente, pode explicar o elevado escore para o fator da Restrição Social para o Grupo $1(7,5)$ e para o Grupo $2(7,4)$. Assim, o Autoritarismo e a Benevolência de familiares, do Grupo 1 e do Grupo 2, podem interferir, de modo negativo, na tomada de decisões de seus parentes portadores de transtornos mentais, desestimulando a sua autonomia. De certa forma, a atitude de Benevolência pode ser contraintuitiva, vendo os portadores de transtornos mentais como crianças inocentes, podem levar a comportamentos não de ajuda, mas de restrições, de modo geral. Entendendo, então, os portadores de transtornos mentais dessa maneira, também pode gerar percepções de irresponsabilidade, e, por sua vez, pode levar a reações de raiva e de evitação (CORRIGAN et al., 2001). Portanto, os familiares do Grupo 1, com escores elevados para Benevolência e Restrição Social, mostram tendência para a superproteção e o hiperenvolvimento, intensificando os conflitos e dificultando os acordos; pois, com a presença do transtorno mental, a família, principalmente o cuidador do parente portador de transtorno mental, tende a colocá-lo no lugar de incapaz, acreditando, assim, que essa pessoa, portadora de transtorno mental, não tem condições de ser responsável pelos seus atos, escolhas e atitudes, adotando uma postura infantilizada de cuidados (PIMENTA; RAMAGNOLI, 2008). Esses resultados seriam mais esperados no Grupo 2, onde os familiares se mantêm mais como cuidadores diretos e têm, inclusive, ajuda de outros. No entanto, a participação no grupo de autoajuda pode estar contribuindo para comportamento de familiares do Grupo 1 mais adequado com o seu parente portador de transtorno mental, pois, no fator Autoritarismo, mesmo com escore relativamente elevado, há diferença significativa quando comparado ao Grupo 2, que é extremamente elevado.

Outro fator com resultados estatisticamente significativos favoráveis ao Grupo 1 foi o fator C, Ideologia de Higiene Mental. Nesse fator, os escores mais elevados representam uma aderência maior a atitudes mais positivas, frente aos transtornos mentais e seus portadores, diferente dos outros fatores. Assim sendo, os familiares que participam do grupo de autoajuda acreditam mais que seus parentes portadores de transtornos mentais se assemelham às pessoas normais e podem desempenhar atividades especializadas, e, isso pode ser atribuído à participação no grupo de autoajuda, onde as trocas de experiências são realizadas e os familiares recebem, a todo o momento, retornos das evoluções dos diversos parentes dos familiares participantes em relação aos seus envolvimentos com atividades produtivas, 
algumas, inclusive, remuneradas. Esse retorno pode ser traduzido em apoio, que leva confiança maior, e, com isso, à volta a uma vida relativamente normal (CHATTERJEE et al., 2009; NGUYEN et al., 2009). Isso, de certa forma, também explica o comportamento de maior autonomia que o familiar que participa do grupo de autoajuda tem para com o seu parente portador de transtorno mental, mesmo que, ainda, suas atitudes parecem ser autoritárias e discriminativas.

Em relação à Etiologia Interpessoal, fator E, o Grupo 1 apresentou escore Sten de 3,9 e o Grupo 2 apresentou o escore Sten de 3,4. Ele revela a perspectiva de que o transtorno mental tem origem em vivências interpessoais, com foco especial na interação com as figuras parentais (RODRIGUES, 1983). Como mostra a Tabela 1, não houve diferença estatisticamente significante também nesse fator, e os escores Sten baixos apresentados refletem que os familiares não acreditam tanto que os transtornos mentais se originam de relações interpessoais, principalmente com parentes que convivem com os referidos transtornos. Isso pode ser explicado pelo fato de os familiares do Grupo 1 terem boas informações, obtidas através do grupo de autoajuda, e os familiares do Grupo 2, mais carentes de informações sobre os transtornos mentais, de um modo geral, não têm oportunidade de refletirem muito sobre esses aspectos. De certa forma, considera-se que os dois grupos podem ter crenças em outras bases de origem dos transtornos mentais, como a visão biológica, a instabilidade emocional, a perda do padrão de normalidade ou predisposição hereditária (RODRIGUES; FIGUEIREDO, 2003).

A Etiologia de Esforço Mental, representada pelo fator $F$, apresentou o escore Sten 6 para o Grupo 1 e 6,8 para o Grupo 2, não apresentando, no entanto, significância estatística como mostra a Tabela 1. Esse fator reflete, conforme já mencionado, a concepção de que o transtorno mental tem origem no excessivo esforço mental, por meio da atividade intelectual intensa, por pensar demais ou negativamente. Nesse contexto, as pessoas que são intelectualmente, ou moralmente, frágeis e que não têm controle consciente das suas emoções estão muito mais sujeitas ao transtorno mental (RODRIGUES, 1983). Então, de modo semelhante, os dois grupos de familiares, participantes deste estudo, entendem que a instabilidade emocional é o eixo da concepção do transtorno mental e ela se dá porque a instabilidade perturba as relações afetivas, provocando o descontrole emocional da pessoa, nas relações familiares, conforme mostram também Rodrigues e Figueiredo (2003). 
O último fator da OTM, fator G, avalia a Visão Minoritária, apresentando, no Grupo 1, escore Sten de 5,6 e no Grupo 2, escore Sten de 6,5. Esse fator descreve a visão de que o portador de transtorno mental pode ser facilmente detectado num agrupamento humano, por ser muito diferente, particularmente na sua aparência externa (RODRIGUES, 1983). É de entendimento que forte aderência a esse fator pode ser traduzido em uma ligação ao estigma sobre o transtorno mental. Assim, o Grupo 2 apresenta-se como mais aderente a essa ideia, tornando mais forte o referido estigma. O Grupo 1 tem uma postura mais adequada nesse sentido, provavelmente favorecido pelas trocas de experiências proporcionadas pelo grupo de autoajuda que, certamente, aproxima mais esse familiar de seu parente com diagnóstico de transtorno mental, e, com o tempo de participação no grupo de autoajuda, ele fica também mais familiarizado com os transtornos mentais e seus portadores, tornando, assim, mais fácil de aceitá-los e compreendê-los. Assim sendo, associando também ao tempo de convívio do Grupo 1 com seu parente portador desses transtornos, é possível inferir que a familiaridade com o portador de transtorno mental e com o trastorno mental, propriamente, pode diminuir 0 preconceito e o estigma, mostrando a importância da educação e do contato com programas ou grupos que promovam a referida familiaridade (CORRIGAN et al., 2001).

De modo geral, pode-se inferir que o grupo de autoajuda interfere positivamente nas atitudes de familiares de portadores de transtornos mentais frente a esses transtornos e seus portadores em diversos aspectos que, certamente, levam à compreensão e aceitação melhor de seu parente com diagnóstico de transtorno mental, mas é importante considerar que essa influência é relativa, pois esse familiar ainda persiste com pensamento tradicional e conservador que levam, ainda, a atitudes de certa forma negativas, sendo traduzidas em atitudes autoritárias, caritativas, restritivas e discriminadoras, como apontou a OTM. Outra consideração importante é o fato dos grupos de autoajuda, que se iniciaram há mais de 70 anos, serem utilizados por portadores de transtornos mentais e seus familiares há cerca de 10 anos e de um modo muito tímido, reservado à algumas cidades e vinculados à Associações, como é o caso da Fênix - Associação Pró Saúde Mental na cidade de São Paulo e a AAPSI - Associação de Apoio ao Psicótico na cidade de Ribeirão Preto, entre poucas outras. Não foram encontrados na literatura estudos desses grupos utilizados na assistência em psiquiatria e saúde mental, o que dificultou a 
discussão do presente estudo. Portanto, pode-se considerar, finalmente, que este é um estudo pioneiro, incentivando, assim, a realização de diversos outros, trazendo dados para discussões mais profundas. 
A partir dos resultados obtidos no presente estudo e da sua discussão é possível concluir que:

- são poucos os familiares de portadores de transtornos mentais que mantêm sua participação no grupo de autoajuda por períodos de tempo mais extensos, ficando tal participação limitada aos momentos mais difíceis do parente portador dos referidos transtornos, onde há grande produtividade de sintomas, e se afasta do grupo nos períodos estabilidade dos transtornos;

- em ambos os grupos pesquisados a faixa etária do familiar, em sua grande maioria, está acima dos 50 anos, são do sexo feminino, mães, casadas e da religião católica. A situação econômica dos familiares participantes do grupo de autoajuda é melhor e eles se sentem mais autônomos frente a seus parentes portadores de transtornos mentais, com mais atividades fora do lar;

- os familiares participantes do estudo têm tempo considerável de convívio com os transtornos mentais, todos acima de 5 anos, e a esquizofrenia é o transtorno mais frequente;

- os familiares participantes do estudo mostraram-se autoritários frente a seus parentes portadores de transtornos mentais, isso mais presente, significativamente no grupo de familiares que não participam do grupo de autoajuda;

- os familiares participantes do grupo de autoajuda mostraram-se mais caritativos frente a seu parente portador de transtorno mental do que os familiares que não participam de grupo de autoajuda, com diferença significativa;

- os familiares participantes do grupo de autoajuda acreditam que seus parentes portadores de transtornos mentais se assemelham às pessoas normais e podem desempenhar atividades especializadas, mais do que os familiares que não participam de grupo de autoajuda, com diferença significativa;

- os familiares pesquisados acreditam pouco que transtorno mental têm origem em vivências interpessoais e acreditam mais que os transtornos mentais tem origem no excessivo esforço mental, por meio da atividade intelectual intensa, por pensar demais ou negativamente;

- os familiares participantes do grupo de autoajuda são menos preconceituosos e estigmatizantes frente aos transtornos mentais e seus portadores do que os familiares que não participam de grupo de autoajuda;

- o grupo de autoajuda tem influência positiva nas atitudes de familiares de portadores de transtornos mentais frente aos transtornos mentais e seus parentes 
portadores desses transtornos, mas essa influência é relativa, pois eles ainda mantêm atitudes autoritárias, caritativas, restritivas e discriminativas;

- o grupo de autoajuda mostrou-se extremamente importante e expressiva ferramenta de apoio, pois os escores da OTM, obtidos de familiares que participam desse grupo, estiveram mais adequados, com diferenças estatísticas significativas em 2 fatores e diferenças importantes em outros fatores, quando comparados com os escores de familiares que não participam de grupos de autoajuda, mas, considera-se que, para real mudança de atitudes nos aspectos considerados, são necessárias modalidades terapêuticas mais específicas e que utilizem intervenções mais focadas, coordenadas ou dirigidas por profissionais especializados;

- destaca-se que o presente estudo teve limites, como: o número pequeno de sujeitos, a pesquisa desenvolvida em apenas um grupo de autoajuda de familiares de portadores de transtornos mentais e a não consideração da frequência de participação no referido grupo, pois só foi considerado o tempo de participação. Assim, considera-se que este é um primeiro estudo que, certamente, abre espaços para a realização de diversos outros, com populações maiores, na busca por mostrar outras contribuições do grupo de autoajuda, quando realizado com portadores de transtornos mentais, parentes e pessoas próximas desses portadores, além da continuidade de estudos com essa modalidade de grupo, ainda no sentido de verificação da sua real condição de interferir nas atitudes de familiares de portadores de transtornos mentais, frente a esses transtornos e seus parentes portadores, tornando-as mais adequadas e direcionadas à melhor compreensão, respeito, aceitação, e abrindo espaços para sua autonomia, aceitação do desafio da inclusão dessa pessoa, que tanto sofre, em uma sociedade que tanto exclui. 
Referências $\mathbf{5 2}$

REFERÊNCIAS 
ABELSON, R. P. Script processing in attitude formation and decision making. In: CARROLL, J. S.; PAYNE J. W. (Eds.). Cognition and social behavior. Hillsdale: Erlbaum, 1976. p. 33-45.

ABREU, A. C. S. S. A atitude dos enfermeiros perante a pessoa com doença mental. 2010. 194 f. Dissertação (Mestrado) - Universidade Católica Portuguesa, Braga, 2010.

AJZEN, I. Attitudes, personality and behavior. Milton Keynes: Open University Press, 1988.

ALMEIDA, L. S. Mãe, cuidadora e trabalhadora: as múltiplas identidades de mães que trabalham. Rev. Dep. Psicol - UFF, Niterói, v. 19, n. 2, p. 411422, jul./dez. 2007.

ALLPORT, G. W. Attitudes. In: MURCHISON, C. (Ed.). Handbook of social psychology. Worcester: Clark University Press, 1935.

AMARANTE, P. (Coord.). Loucos pela vida: a trajetória da reforma psiquiátrica no Brasil. 2. ed. Rio de Janeiro: Fiocruz, 2001.

AMARANTE, P. Psiquiatria social e reforma psiquiátrica. Rio de Janeiro: Fiocruz, 1994.

ARVANITI, A.; SAMAKOURI, M.; KALAMARA, E.; BOCHTSOU, V.; BIKOS, C.; LIVADITIS, M. Health service staff's attitudes towards patients with mental illness.

Soc. Psychiatry Psychiatr. Epidemiol., v. 44, n. 8, p. 658-665, 2008.

AVANCI, R. C.; MALAGUTI, S. E.; PEDRÃO, L. J. Autoritarismo e benevolência frente à doença mental: estudo com alunos ingressantes no curso de enfermagem. Rev. Latino-am. Enfermagem, Ribeirão Preto, v. 10, n. 4, p. 509-515, jul./ago. 2002.

AZEVEDO, D. M.; MIRANDA, F. A. N.; GAUDÊNCIO, M. M. P. Percepções de familiares sobre o portador de sofrimento psíquico institucionalizado. Esc. Anna Nery Rev. Enferm, Rio de Janero, v. 13, n. 3, p. 485-491, jul./set. 2009.

BEM, D. J. Self-Perception: An alternative interpretation of cognitive dissonance phenomena. Psychological Review, v.74, p.183-200, 1967.

BRASIL. Ministério da Saúde. Conselho Nacional de Saúde. Diretrizes e normas regulamentadores de pesquisas envolvendo seres humanos. 1996. Disponível em: <http://www.bioetica.ufrgs.br/res19696.htm\#cep>. Acesso em: jan. 2009.

BRASIL. Ministério da Saúde. DATASUS. Sistema de Informações Hospitalares do SUS. 2011. Disponível em: <http://www.datasus.gov.br>. Acesso em: maio de 2011.

CANFIELD, A. A. The sten scale: a modified C - scale. Educ. Psychol. Meas., Cidade, v. 11, p. 295-297, 1951. 
CAVASSA, N. Psicologia das atitudes e das opiniões. São Paulo: Loyola, 2008.

CHATTERJEE, S.; PILLAI, A.; JAIN, S.; COHEN, A.; PATEL, V. Outcomes of people with psychotic disorders in a community-based rehabilitation programme in rural India. Br. J. Psychiatry, London, v. 195, n. 5, p. 433-439, nov. 2009.

COHEN, J.; STRUENING, E .L. Opinions about mental illness in the personnel of two large mental hospitals. J. Abnorm. Soc. Psychol., Washington, v. 64, n. 5, p. 349360, 1962.

COLVERO, L. A.; IDE, C. A. C.; ROLIM, M. A. Família e doença mental: a difícil convivência com a diferença. Rev. Esc. Enferm. USP, São Paulo, v. 38, n. 2, p. $197-$ 205, 2004.

CORRIGAN, P. W.; EDWARDS, A. B.; GREEN A.; DIWAN, S. L.; PENN, D. L. Prejudice, Social Distance, and Familiarity with Mental Illness. Schizophrenia Bull., Oxford, v. 27, n. 2, p. 219-225. 2001.

CRITÉRIO DE CLASSIFICAÇÃO ECONÔMINA BRASIL - Associação Brasileira de Empresas de Pesquisa (Abep). Dados com base no Levantamento Sócio Econômico 2008 - IBOPE. 2010. Disponível em: <http://www.abep.org>. Acesso em: março de 2010.

ELSEN, I. Saúde familiar: a trajetória de um grupo. In: Marcos para a prática com famílias. Florianópolis: Editora da UFSC, 1994.

FERREIRA, A. B. H. Novo Aurélio - O dicionário da Lingua Portuguesa. 3. ed. Rio de Janeiro: Nova Fronteira, 2004.

FISHBEIN, M.; AJZEN, I. Belif, attitude, intention and behavior: an introdution to theory and research. Boston: Addison - Wesley, 1975.

GOES, A. R. M. Cuidadores (as) de portadores de transtornos mentais e a família no contexto da desinstitucionalização. 2007. 128 f. Dissertação (Mestrado) - Universidade Estadual de Londrina, Londrina, 2007.

GOES, A. R. M.; CARMO, L. H. M. Cuidadora de portador de transtorno mental - um foco de análise. Serv. Soc. Rev., Londrina, v. 7, n. 2, jan./jul. 2005.

HAMAIDEH, S.; MUDALLAL, R. Attitudes of jordanian nursing students towards mental illness: the effect of teaching and contact on attitudes change. Col. Stud. J., v. 43 , p. 335-346, jun. 2009.

HANSON, S. M. H.; BOYD, S. T. Family health care nursing - theory, practice, and research. Philadelphia: F. A. Davis, 1996.

HENZ, R. C. O perfil do cuidador familiar e suas necessidades com relação aos cuidados prestados ao idoso com dependência em uma estratégia de saúde da família. 2011. 49 f. (Monografia) - Escola de Enfermagem, Universidade Federal do Rio Grande do Sul, Porto Alegre, 2011. 
HOOD, R. W., JR. Dogmatism and opinions about mental illness. Psychol. Rep, v. 32, p. 1283-1290, 1973.

JASPARS, J. Attitudes. In: HARRÉ, R.; LAMB, R. (Eds.). The dictionary of personality and social psychology. Oxford: Basil Blackwell, 1986.

JUCÁ, V. J. S. Multiple voices of healing in mental health: an analysis of psychiatric discourse. Cienc. Saúde Coletiva, Rio de Janeiro, v. 10, n. 3, p. 771-779, 2005.

KAPLAN, H. I.; SADOCK, B. J.; GREEB, J. A. Compêndio de psiquiatria. Porto Alegre: Artes Médicas, 1997.

LYMAN, H. B. Derived scores. In:

Prentice-Hall, 1963. chap. 6, p. 90-136.

Test scores and what they mean.

MARQUES, S. Cuidadores familiares de idosos: relatos de histórias. $186 \mathrm{f}$. Dissertação (Mestrado) - Escola de Enfermagem de Ribeirão Preto, Universidade de São Paulo, Ribeirão Preto, 2000.

MINAYO, M. C. O desafio do conhecimento: pesquisa qualitativa em saúde. 8. ed. São Paulo: Hucitec-Abrasco, 2004.

MIRANDA, C. A.; TARASCONI, C. V.; SCORTEGAGNA, S. A. Estudo epidêmico dos transtornos mentais. Av. Psicol., Porto Alegre, v. 7, n. 2, p. 249-257, 2008.

MURARO, R. M.; BOFF, L. Feminino e masculino: uma nova consciência para o encontro das diferenças. Rio de Janeiro: Sextante, 2002.

NGUYEN, T. A.; OOSTERHOFF, P.; NGOC, Y. P.; WRIGHT, P.; HARDON, A. Selfhelp groups can improve utilization of postnatal care by HIV-infected mothers. J. Assoc. Nurs. Aids Care, Akron, v. 20, n. 2, p. 141-152, may/apr. 2009.

NAKATANI, A. Y. K.; SOUTO, C. C. S.; PAULETTE, L. M.; MELO, T. S.; SOUZA, M. M. Perfil dos cuidadores informais de idosos com déficit de autocuidado atendidos pelo Programa de Saúde da Família. Rev. Eletr. Enferm., Goiânia, v. 5, n. 1, 2003. Disponível em: <http:/www.fen.ufg.br/revista>. Acesso em: maio de 2011.

NERI, A. L.; SOMMERHALDER, C. As várias faces do cuidado e do bem-estar do cuidador. In: Cuidar de idosos no contexto da família: questões psicológicas e sociais. Campinas: Alínea, 2002.

NUNNALY, J. C., JR. Popular concepts of mental health, their development and change. New York: Holt, Rinehart \& Winston, 1961.

OLIVEIRA, R. M. P.; LOYOLA, C. M. Família do paciente psiquiátrico: o retrato de uma ilustre desconhecida. Acta Sci. Health Sci., Maringá, v. 26, n. 1, p. 213-222, 2004.

OSÓRIO, L. C. Família hoje. Porto Alegre: Artes Médicas, 1996. 
PIMENTA, E. S.; ROMAGNOLI, R. C. A relação com as famílias no tratamento dos portadores de transtorno mental realizado no Centro de Atenção Psicossocial. Pesquisas e Práticas Psicossociais, São João Del Rei, v.3, n.1, p.75-84, ago. 2008.

PEDRÃO, L. J.; AVANCI, R. C.; MALAGUT, S. E.; AGUILERA, A. M. S. Atitudes frente à doença mental: estudo comparativo entre ingressantes e formandos em enfermagem. Medicina, Ribeirão Preto, v. 36, p. 37-44, jan./mar. 2003.

PEDRÃO, L. J.; GALERA, S. A. F.; SILVA, M. C. P.; GONZALEZ, A.C.; COSTA, M. L. JR.; SOUZA, M. C. B. M.; et al. Perfil das atitudes de formandos em enfermagem frente aos transtornos mentais no Brasil, Chile e Peru. Rev. Latino-am. Enfermagem, Ribeirão Preto, v. 13, n. 3, p. 339-433, mai./jun. 2005.

PRADO, D. O que é família. São Paulo: Brasiliense, 1981.

RIBEIRO, M. T. F.; FERREIRA, R. C.; FERREIRA, E.; MAGALHÃES, C. S.; MOREIRA, A. N. Perfil dos cuidadores de idosos nas instituições de longa permanência de Belo Horizonte, MG. Ciênc. Saúde Coletiva, Rio de Janeiro, v. 13, n. 4, p.1285-1292, jul./ago. 2008.

RODRIGUES, C. R. C. Atitudes frente à doença mental: estudo transversal de uma amostra de profissionais da saúde. 1983. 150 f. Dissertação. (Doutorado) Faculdade de Medicina de Ribeirão Preto, Universidade de São Paulo, Ribeirão Preto, 1983.

RODRIGUES, C. R. C. Comparacion de actitudes de estudiantes de medicina braileños y españoles hacia la enfermedad mental. Actas Luso-Españoles Neurol. Psiquiatr. Ciênc. Afines, v. 20, n. 1, p. 30-41, 1992.

RODRIGUES, C. R.; FIGUEIREDO, M. A. C. Concepções sobre a doença mental em profissionais, usuários e seus familiares. Estud. Psicol., Campinas, v. 8, n. 1, p. 117-125, 2003.

ROSENBERG, M. J.; HOVLAND, C. I. Attitude, organization and change: an analysis of consistency among attitude components. New Haven: Yale University Press, 1960.

SILVA, M. B.; SADIGURSKY D. C. Representações sociais sobre o cuidar do doente mental no domicílio. Rev. Bras. Enfermagem, Brasília, DF, v. 61, n. 4, p. 428-344, jul /ago. 2008.

SOARES, C. B.; MUNARI, D. B. Considerações acerca da sobrecarga em familiares de pessoas com transtornos mentais. Ciênc. Cuid. Saúde, Maringuá, v. 6, n. 3, p. 357-362, jul./set. 2007.

SOCCI, V. Religiosidade e o adulto idoso. In: Envelhecimento: referenciais teóricos e pesquisas. São Paulo: Alínea, 2006. 
SPADINI, L. S.; SOUZA, M. C. B. M. A doença mental sob o olhar de pacientes e familiares: [revisão]. Rev. Esc. Enferm. USP, São Paulo, v. 40, v. 1, p. 123-127, mar. 2006.

STRUENING, E. L.; COHEN, J. Fatorial invariance and other psychometric characteristics of five opinions about mental illness fators. Educ. Psychol. Meas. v. 23, n. 3, p. 289-298, 1963.

Thomas, W I \& Znaniecki, F. The Polish Peasant in Europe and America. Chicago: University of Chicago Press, v. 1 e 2, p 21-22, 1918-1920.

VALA, J. MONTEIRO, M. B. Psicologia social. 7. ed. Lisboa: Fundação Calouste Gulbenkian, 2006. cap. 8.

ZIMERMAN, D. E. Fundamentos básicos das grupoterapias. Porto Alegre: Artes Médicas, 1993.

ZIMERMAN, D. E.; OSÓRIO, L. C. Como trabalhamos com grupos. Porto Alegre: Artmed, 1997. 


\section{APÊNDICE A \\ QUESTIONÁRIO \\ Parte A - Dados Pessoais}
A) Sexo: (1) Masculino
(2) Feminino
B) Idade: anos.
C) Religião:
(1) Católica
(2) Espírita
(3) Evangélica
(4) Outra (especificar)
(5) Não tem Religião

D) Estado Civil:

(1) Solteiro

(2) Casado

(3) Viúvo

(4) Desquitado/Divorciado

(5) Outros

D) Procedência:

(1) Ribeirão Preto

(2) Região de Ribeirão Preto

(3) Estado de São Paulo

(4) Outro Estado

\section{Parte B - Contato com Portador de Transtorno Mental}

Quando foi o início do Transtorno Mental?

Quando o paciente iniciou no grupo de autoajuda?

Quando o cuidador iniciou nesse grupo?

Qual o grau de parentesco com o paciente?

Mora junto com o paciente?

Existe outro cuidador?

Sempre dividiu os cuidados? 
Trabalha/Estuda fora?

O cuidar atrapalha sua vida hoje?

Já atrapalhou no passado?

Pode dizer o diagnóstico de seu familiar portador de transtorno mental?

\section{Critério de Classificação Econômica Brasil}

\begin{tabular}{|l|l|l|l|l|l|}
\hline Posse de itens & \multicolumn{5}{|c|}{ Quantidade de Itens } \\
\hline Televisão em cores & 0 & 1 & 2 & 3 & 4 ou + \\
\hline Rádio & & & & & \\
\hline Banheiro & & & & & \\
\hline Automóvel & & & & & \\
\hline Empregada Mensalista & & & & & \\
\hline Máquina de Lavar & & & & & \\
\hline Videocassete e/ou DVD & & & & & \\
\hline Geladeira (aparelho \\
$\begin{array}{l}\text { Freezer ou } \\
\text { independente } \\
\text { geladeira duplex) }\end{array}$ & & & & \\
\hline
\end{tabular}

\begin{tabular}{|l|l|l|}
\hline \multicolumn{3}{|c|}{ Grau de Instrução do Chefe de Família } \\
\hline Analfabeto / Primeiro grau incompleto & \multicolumn{1}{|c|}{$\begin{array}{c}\text { Analfabeto } / 3^{\circ} \text { Serie } \\
\text { Fundamental }\end{array}$} & \\
\hline Primário Incompleto / Ginasial Incompleto & Até 4 Serie Fundamental & \\
\hline Ginasial Completo / Colegial Incompleto & Fundamental Completo & \\
\hline Colegial Completo / Superior Incompleto & Médio Completo & \\
\hline Superior Completo & Superior Completo & \\
\hline
\end{tabular}




\section{APÊNDICE B}

\section{TERMO DE CONSENTIMENTO LIVRE E ESCLARECIDO}

\section{Convidamos o(a) senhor(a)}

portador de Cédula de Identidade R.G. no

abaixo

assinado, para participar da pesquisa intitulada: Atitudes de familiares de portadores de transtornos mentais frente aos transtornos mentais: estudo transversal, onde o(a) senhor(a) responderá um questionário contendo os seus dados pessoais e perguntas sobre o contato que o senhor(a) tem com o seu familiar portador de transtorno mental. Depois, o senhor(a) preencherá outro questionário onde dará a sua opinião sobre os transtornos mentais e sobre os portadores desses transtornos. Para isso, o senhor(a) demorará aproximadamente 30 minutos. Este convite está sendo feito, devido o senhor(a) ser participante do Grupo de Auto Ajuda da Associação de Apoio ao Psicótico (AAPSI), e, assim, sua participação contribuirá mostrando a eficiência deste grupo no sentido de possibilitar, devido a troca de experiências, uma compreensão melhor do familiar portador dos referidos transtornos, e, consequentemente, um convívio melhor com eles.

Esta pesquisa garante ao(a) senhor(a) o direito de receber resposta a qualquer pergunta, ou esclarecimento a qualquer dúvida, sobre os procedimentos que serão realizados. $O(A)$ senhor(a) não correrá nenhum risco e esperamos que tenha muitos benefícios, entre eles, que o Grupo de Auto Ajuda da AAPSI e outros possam contribuir mais na melhora de seu relacionamento com o seu familiar que convive com um transtorno mental. Garante que o(a) senhor(a) não terá nenhum gasto e que terá liberdade para deixar de participar da pesquisa quando quiser, sem que isso traga prejuízo à continuação da sua participação no Grupo de Auto Ajuda da AAPSI .

Garante a segurança de que não será identificado e que serão mantidas em segredo as informações que o(a) senhor(a) nos falar. Garante o compromisso de proporcionar informação atualizada durante a pesquisa, ainda que possa afetar sua vontade de continuar participando. Finalmente, garante o compromisso de que será devidamente acompanhado e assistido durante todo o período de participação, bem como garante a continuidade dos cuidados após a conclusão dos trabalhos da mesma.

Tenho ciência do exposto acima, inclusive da publicação destes resultados em revistas de pesquisa e declaro livremente minha vontade de participar. Este termo vai em duas vias, ficando uma com o(a) senhor(a) para contato conosco, quando for necessário.

Ribeirão Preto, de de 2009.

Pesquisadores responsáveis:

Nome legível e assinatura do familiar

Angelina Moda Machado - Telefone: (16) 34422674 - Av. do Café, 1715 - CEP 14050-230 - Ribeirão Preto SP, e-mail: angelina_moda@yahoo.com.br

Profo ${ }^{\circ}$. Dr. Luiz Jorge Pedrão - Telefone: (16) 36023418 EERP-USP - Campus USP Av. Bandeirantes, 3900 - CEP - 14040-902 - Ribeirão Preto SP, e-mail: lujope@eerp.usp.br 


\section{ANEXO A \\ OPINIÕES SOBRE O TRANSTORNO MENTAL (OTM) \\ INSTRUÇÕES}

As afirmações que se seguem, a partir da próxima página, são opiniões ou idéias sobre o portador de transtorno mental e os transtornos mentais. Por transtorno mental, entendem-se todos os tipos de transtornos que levam à internação da pessoa em um hospital psiquiátrico ou que exige assistência freqüente em algum serviço de assistência psiquiátrica ou de saúde mental, e, por portador de transtorno mental, toda pessoa que necessitou de internação em um hospital psiquiátrico e posteriormente precisou de acompanhamento específico em serviços de assistência psiquiátrica ou de saúde mental, ou, não necessitou internação psiquiátrica, mas faz seguimento freqüente em algum serviço de assistência psiquiátrica ou de saúde mental, ou, ainda, que precisa de algum acompanhamento por profissional da área de psiquiatria ou saúde mental.

As opiniões são extremamente variáveis quanto a esses aspectos. Assim, muitas pessoas concordarão com várias das afirmações seguintes, enquanto que outras tantas discordarão das mesmas. Para o nosso trabalho é importante saber a sua maneira de pensar, e, dessa forma, pedimos que siga as instruções seguintes:

No final de cada uma das 51 afirmações apresentadas a seguir, há um quadrado, no qual você deverá colocar um número correspondente às alternativas:

\section{1 - Concordo totalmente}

\section{2 - Concordo}

\section{3 - Em dúvida, mas provavelmente concordo}

\section{4 - Em dúvida, mas provavelmente discordo}

\section{5 - Discordo}

\section{6 - Discordo totalmente}

A alternativa que você escolher certamente é a mais próxima daquilo que pensa sobre a afirmação. Esteja certo de que muitos profissionais afins concordarão com a sua escolha. Não existem alternativas certas ou erradas. Estamos interessados apenas em sua opinião. É muito importante que você responda a todas as afirmações

1. O esgotamento nervoso geralmente ocorre quando as pessoas trabalham demais .

2. O transtorno mental é um transtorno ou doença como outro qualquer. 
3. A maioria das pessoas portadoras de transtornos mentais de hospitais psiquiátricos não é perigosa.

4. Ainda que as pessoas portadoras de transtornos mentais possam ter um aspecto sadio após terem recebido alta de um hospital psiquiátrico, elas não deveriam ter permissão para se casar.

5. Se os pais amassem mais os seus filhos, haveria menos transtornos mentais.

6. É fácil de se reconhecer alguém que já teve um transtorno mental grave.

7. As pessoas que sofrem de algum transtorno mental deixam-se dominar pelas emoções; as pessoas normais controlam-nas.

8. As pessoas que já foram pacientes em hospitais psiquiátricos não são mais perigosas do que uma pessoa comum.

9. Quando alguém tem um problema ou uma preocupação, é melhor não pensar no assunto e manter-se ocupado com coisas mais agradáveis.

10. Muitas pessoas adquirem transtorno mental para fugirem dos problemas difíceis da vida cotidiana, apesar de geralmente não estarem conscientes disto.

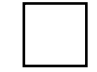

11. Existe alguma coisa nos portadores de transtornos mentais que torna fácil distingui-los das pessoas normais.

12. Não se deve rir de pessoas portadoras de transtornos mentais internadas nos hospitais psiquiátricos, mesmo que eles se comportem de forma cômica.

13. A maioria dos portadores de transtornos mentais deseja trabalhar.

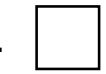

14. Não se deve permitir que as crianças visitem seus pais internados em hospitais psiquiátricos.

15. As pessoas bem sucedidas no trabalho raramente adquirem transtorno mental.

16. As pessoas não adquiririam transtorno mental se evitassem pensamentos negativos. 
17. Os portadores de transtornos mentais em hospitais psiquiátricos são, sob muitos aspectos, como crianças.

18. Deveriam ser liberadas mais verbas federais para o cuidado e tratamento de pessoas portadoras de transtornos mentais graves.

19. Um portador de transtorno mental é completamente diferente de portadores de outros transtornos ou doenças, como por exemplo, dos pacientes cardíacos.

20. Os portadores de transtornos mentais são provenientes de lares onde os pais pouco se interessavam pelos filhos.

21. Pessoas portadoras de transtornos mentais nunca devem ser tratadas no mesmo hospital que pessoas com doenças físicas.

22. Qualquer pessoa que firmemente tenta progredir merece o respeito alheio.

23. Se nossos hospitais psiquiátricos tivessem um número suficiente de médicos, enfermeiros e auxiliares, bem treinados, muitos portadores de transtornos mentais recuperar-se-iam a ponto de poder viver fora do hospital.

24. Uma mulher é insensata quando se casa com um homem que teve um transtorno mental grave, mesmo que ele aparentemente esteja totalmente recuperado.

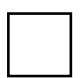

25. Se filhos de pais portadores de transtornos mentais fossem criados por um casal normal, provavelmente não se tornariam portadores de transtornos mentais.

26. As pessoas que já foram internadas em um hospital psiquiátrico jamais serão como antes.

27. Muitos portadores de transtornos mentais são capazes de desempenhar um trabalho especializado, mesmo sendo, em alguns aspectos, muito perturbados mentalmente.

28. Nossos hospitais psiquiátricos se parecem mais com prisões do que com locais onde portadores de transtorno mental possam ser cuidados.

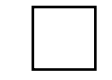


29. Não se deve permitir que uma pessoa internada em hospital psiquiátrico vote.

30. O transtorno mental de muitas pessoas é causado pela separação ou divórcio de seus pais durante a infância.

31. A melhor forma de se lidar com portadores de transtornos mentais em hospitais psiquiátricos é mantê-los a portas trancadas.

32. Internar-se em um hospital psiquiátrico é tornar-se um fracasso na vida.

33. Os portadores de transtornos mentais nos hospitais psiquiátricos devem ter direito a maior privacidade, ou seja, deve haver mais respeito à sua individualidade.

34. Se um portador de transtorno mental em um hospital psiquiátrico atacar alguém, deve ser punido para que o fato não se repita.

35. Se filhos de pais normais fossem criados por um casal de portadores de transtornos mentais, provavelmente tornar-se-iam portadores desses transtornos.

36. Todo hospital psiquiátrico deve ser cercado por altos muros e ter vigilantes.

37. Deve ser legalmente permitido que uma mulher se divorcie de seu marido assim que ele seja internado em um hospital psiquiátrico com um transtorno mental grave.

38. As pessoas que estão incapacitadas para o trabalho devido a um transtorno mental devem receber auxílio financeiro para a sua manutenção.

39. O transtorno mental é geralmente causado por algum transtorno ou doença do sistema nervoso.

40. Os portadores de transtorno mental grave deixam de ser realmente humanos.

41. A maioria das mulheres que já foram internadas em hospitais psiquiátricos pode ter crianças pequenas entregues aos seus cuidados.

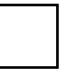


42. A maioria dos portadores de transtornos mentais internados em hospitais psiquiátricos não se preocupa com sua aparência.

43. Os professores universitários têm maior probabilidade de se tornarem portadores de transtornos mentais que os comerciantes.

44. Muitas pessoas que nunca foram internadas em um hospital psiquiátrico possuem sofrimento psíquico maior do que muitos dos portadores de transtornos mentais hospitalizados.

45. Embora alguns portadores de transtornos mentais pareçam estar bem, é perigoso esquecer que são pessoas que possuem este transtorno.

46. Às vezes o transtorno mental é uma punição por erros cometidos.

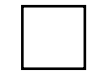

47. Nossos hospitais psiquiátricos deveriam ser organizados de modo a permitir que a pessoa portadora de transtorno mental se sentisse como estivesse em sua própria casa.

48. Uma das principais causas do transtorno mental é a falta de força moral ou força de vontade.

49. Há pouco que possa ser feito pelos portadores de transtornos mentais em hospitais psiquiátricos, além de cuidar para que tenham conforto e estejam bem alimentados.

50. Muitos portadores de transtornos mentais optariam por permanecer no hospital até que estivessem bem, mesmo que o hospital fosse mantido a portas abertas.

51. Todos os portadores de transtornos mentais de um hospital psiquiátrico deveriam ser cirurgicamente impedidos de procriarem.

Aqui terminamos nosso questionário. Por favor, verifique se não deixou algum item ou página sem resposta. Queremos agradecer novamente a contribuição dada ao nosso trabalho, a boa vontade com que fomos recebidos e o tempo dispendido. Muito obrigado. 


\section{ANEXO B}
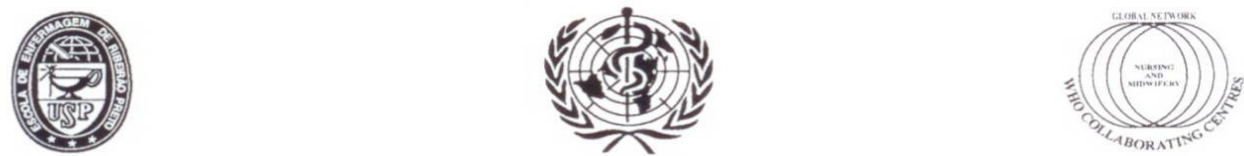

Escola de Enfermagem de Ribeirão Preto - Universidade de São Paulo

Centro Colaborador da Organização Mundial da Saúde para

o Desenvolvimento da Pesquisa em Enfermagem

Avenida Bandeirantes, 3900 - Campus Universitário - Ribcirão Preto - CEP 14040-902 - São Paulo - Brasi

FAX: (55) - 16-3633-3271/ TELEFONE: (55) - 16-3602-3382

COMITÊ DE ÉTICA EM PESQUISA DA EERP/USP

Of.CEP-EERP/USP - 019/2009

Ribeirão Preto, 19 de fevereiro de 2009

Prezado Senhor,

Comunicamos que o projeto de pesquisa, abaixo especificado, foi analisado e considerado APROVADO pelo Comitê de Ética em Pesquisa da Escola de Enfermagem de Ribeirão Preto da Universidade de São Paulo, em sua $114^{a}$ Reunião Ordinária, realizada em 18 de fevereiro de 2009.

Protocolo: $\quad$ n 0998/2009

Projeto: ATITUDES DE FAMILIARES DE PORTADORES DE TRANSTORNOS MENTAIS FRENTE AOS TRANSTORNOS MENTAIS: ESTUDO TRANSVERSAL.

Pesquisadores: Luiz Jorge Pedrão

Angelina Moda Machado

Em atendimento à Resolução 196/96, deverá ser encaminhado ao CEP o relatório final da pesquisa e a publicação de seus resultados, para acompanhamento, bem como comunicada qualquer intercorrência ou a sua interrupção.

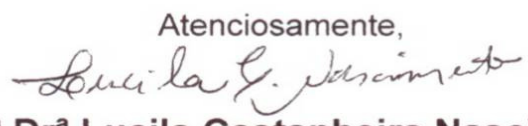

Profa Dra Lucila Castanheira Nascimento Coordenadora do CEP-EERP/USP

IImo. Sr.

Prof. Dr. Luiz Jorge Pedrão

Departamento de Enfermagem Psiquiátrica e Ciências Humanas

Escola de Enfermagem de Ribeirão Preto - USP 